\title{
Spin-forming Project Report
}

Federal Manufacturing \& Technologies

Nathan Switzner and Dick Henry

KCP-613-8550

Published March 2009

\section{Final Report}

Approved for public release; distribution is unlimited.

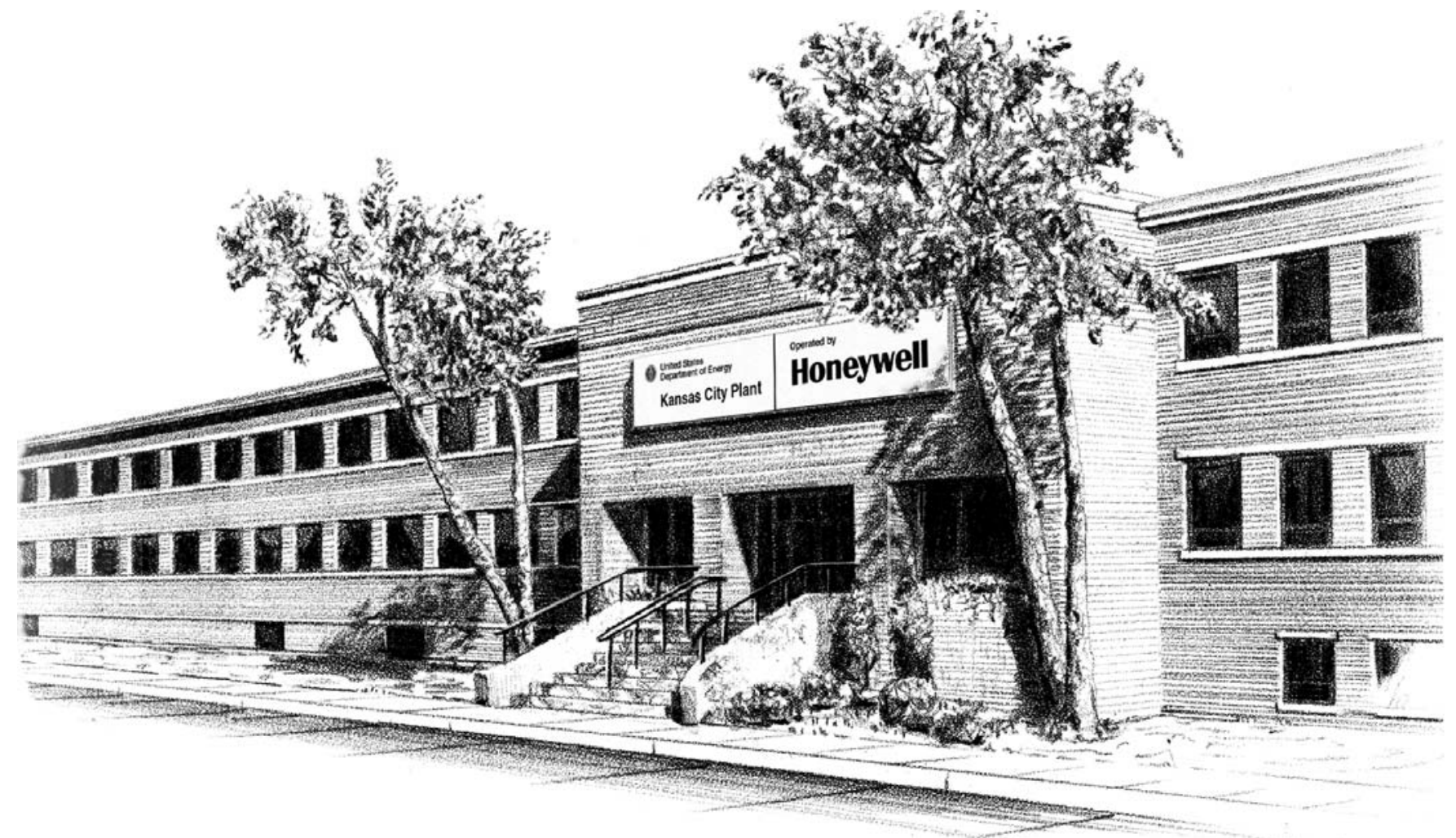

Prepared under prime contract DE-ACO4-01AL66850 for the

United States Department of Energy 


\section{DISCLAIMER}

This report was prepared as an account of work sponsored by an agency of the United States Government. Neither the United States Government nor any agency thereof, nor any of their employees, makes any warranty, express or implied, or assumes any legal liability or responsibility for the accuracy, completeness, or usefulness of any information, apparatus, product, or process disclosed, or represents that its use would not infringe privately owned rights. Reference herein to any specific commercial product, process or service by trade names, trademark, manufacturer, or otherwise, does not necessarily constitute or imply its endorsement, recommendation or favoring by the United States Government or any agency thereof. The views and opinions of authors expressed herein do not necessarily state or reflect those of the United States Government or any agency thereof.

All data prepared, analyzed and presented has been developed in a specific context of work and was prepared for internal evaluation and use pursuant to that work authorized under the reference contract. Reference herein to any specific commercial product, process or service by trade name, trademark, manufacturer, or otherwise, does not necessarily constitute or imply its endorsement, recommendation or favoring by the United States Government, any agency thereof or Honeywell Federal Manufacturing \& Technologies, LLC.

Printed in the United States of America.

This report has been reproduced from the best available copy.

Available to DOE and DOE contractors from the Office of Scientific and Technical Information, P.O. Box 62, Oak Ridge, Tennessee 37831; prices available from (865) 576-8401, FTS 626-8401.

Available to the public from the National Technical Information Service, U.S. Department of Commerce, 5285 Port Royal, Rd., Springfield, Virginia 22161, (703) 487-4650.

A prime contractor with the United States Department of Energy under Contract Number DE-AC04-O1AL66850
Honeywell Federal Manufacturing \& Technologies

P.O. Box 419159

Kansas City, Missouri, 64141-6159 


\section{Honeywell}

KCP-613-8550

Distribution Category UC-42

Approved for public release; distribution is unlimited.

\section{SPIN-FORMING PROJECT REPORT}

Nathan Switzner and Dick Henry

Published March 2009

Final Report

Nathan Switzner, Project Leader

Project Team:

Dick Henry, Dave Jarboe, John Boyd 



\section{Contents}

Section

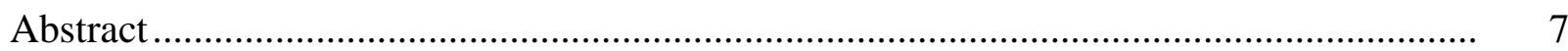

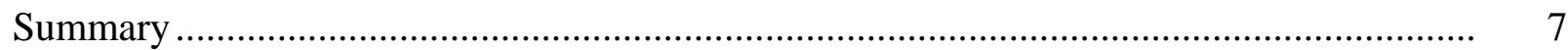

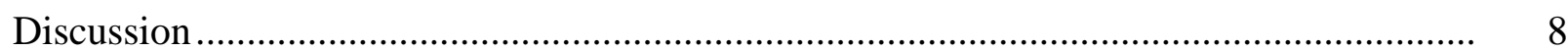

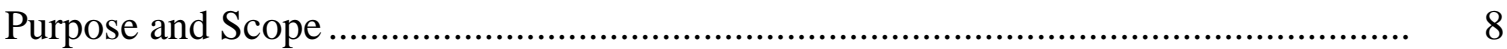

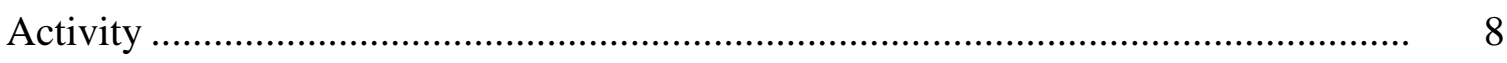

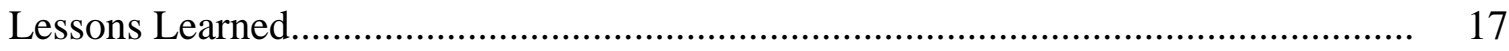

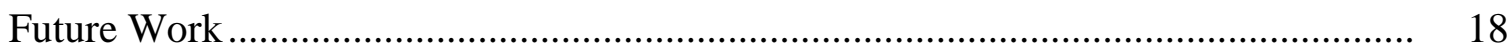

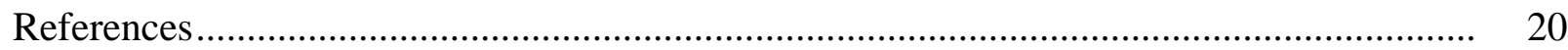

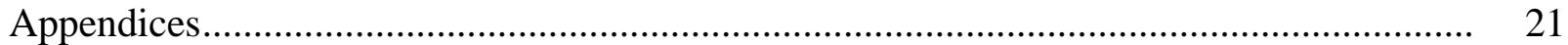

A. Add'l Data for Development 1 Mat'ls (KCP-613-8483) .................................. 23

B. Scope of Work for Spin-Form Development Order 2 ................................... 25

C. Results of Spin-Form Development Order 2 …......................................... 27 


\begin{abstract}
In a second development order, spin-forming equipment was again evaluated using the test shape, a hemispherical shell. In this second development order, pure vanadium and alloy titanium (Ti-6Al-4V) were spin-formed, as well as additional copper and 21-6-9 stainless. In the first development order the following materials had been spin-formed: copper (alloy C11000 ETP), 6061 aluminum, 304L stainless steel, 21-6-9 stainless steel, and tantalum-2.5\% tungsten.
\end{abstract}

Significant challenges included properly adjusting the rotations-per-minute (RPM), cracking at un-beveled edges and laser marks, redressing of notches, surface cracking, non-uniform temperature evolution in the titanium, and cracking of the tailstock. Lessons learned were that 300 RPM worked better than 600 RPM for most materials (at the feed rate of $800 \mathrm{~mm} / \mathrm{min}$ ); beveling the edges to lower the stress reduces edge cracking; notches, laser marks, or edge defects in the preform doom the process to cracking and failure; coolant is required for vanadium spin-forming; increasing the number of passes to nine or more eliminates surface cracking for vanadium; titanium develops a hot zone in front of the rollers; and the tailstock should be redesigned to eliminate the cylindrical stress concentrator in the center.

\title{
Summary
}

The purpose of this report is to record what has been learned through Spin-forming Development Order 2 (KCP-613-8483 was published for Development Order 1). The Purpose and Scope section briefly describes those aspects of Spin-Forming Development 2. For more information on purpose and scope the project manager from the Kansas City Plant (KCP) previously described the background and details for this project in report KCP-613-8483. The Activity section describes the preparation and execution of Development 2; the Lessons Learned section provides the details of some important discoveries; and Future Work lays out the next steps in the project. Most of the data, machine parameters, and pictures are contained in the Appendices. 


\section{Discussion}

The spin-forming team is steadily advancing in the processing know-how of spin-forming and the metallurgy of various spin-formed materials. The initial purpose of the spin-forming project was to replace the antiquated hydro-forming process - that requires a special foundation-in the new KCP facility. For more information on purpose and scope the project manager from the KCP previously described the background and details for this project in report KCP-613-8483 (Ref 1). Potential customers and interested government personnel continue to monitor the progress of spin-forming at the KCP. In addition, KCP engineers are identifying opportunities for spin-forming development or improvement of existing production parts. Pure metal and alloy parts with cylindrical symmetry and wall thicknesses of less than about 0.25 " are potential candidates for spin-forming. Spin-forming helps to produce near-net parts that reduce subsequent machining steps and/or improve final flow and properties.

\section{Purpose and Scope}

The purpose of Spin-forming Development 2 was to test the feasibility of spin-forming pure vanadium and hot-spin-forming alloy titanium (Ti-6Al-4V). The team also wanted to build upon the knowledge from the Development 1 by spin-forming pure copper and 21-6-9 stainless steel. The project scope was to successfully form at least one part from each material, and document the parameters that lead to success. In accordance with that scope, six 21-6-9 parts were successfully formed, and a copper and vanadium part were successfully formed. Titanium alloy showed no complete success, but the pre-forms were impaired by the laser-marked grid pattern and the notched edges, which were stress concentrators leading to premature failure.

\section{Activity}

The team sifted through the spin-forming and flow-forming suppliers listed in the Thomas Register of suppliers and selected six potential suppliers on the bases of computer numerical controlled (CNC) equipment, spin-forming thickness capabilities, willingness to perform aerospace work, and use of American-made spin-forming equipment. The team drew up a Scope of Work (SOW) for Development Order 2 (shown in Appendix A), and sent this document along with a request for information (RFI) to the six selected companies. Their responses are summarized in Table 1. Hess Industries was the only company to agree to provide a complete quote. Although Hess had been late on the shipment of some Development 1 parts and had performed the Development 1 work on equipment too large for the KCP to consider for purchase, the decision was made to order Development 2 from them after confirming that they would improve their responses. The Development 2 work did end up being performed on large equipment again, but the KCP team decided this was acceptable since the primary end was to determine process feasibility. Tables 2 through 4 give the compositions and sources of the experimental materials. 
Table 1 Responses to the Scope of Work (SOW) and Request for Information (RFI)

\begin{tabular}{|c|c|}
\hline Company & Response \\
\hline Hess Industries & - Agreed to quote per the SOW. \\
\hline Glenn Metalcraft & $\begin{array}{l}\text { - Initially agreed to quote, but declined when they found out the } \\
\text { RFI had been sent to several companies. }\end{array}$ \\
\hline Columbia Metal Spinning & $\begin{array}{l}\text { - } 0.25 \text { in. is their maximum thickness. (KCP SOW included } \\
0.325 \text { in. stainless steel and } 0.446 \text { in. vanadium.) } \\
\text { - They have only limited hot spinning experience. } \\
\text { - They have no experience with } 21-6-9 \text { stainless steel. } \\
\text { - Their equipment requires register holes in the blank centers. } \\
\text { - They have CNC playback machines and one digital and playback } \\
\text { machine. } \\
\text { - Although they could not accommodate this order, they are } \\
\text { interested in future business. }\end{array}$ \\
\hline Spincraft & $\begin{array}{l}\text { - The material is too thick for them to work with on their CNC } \\
\text { machines. }\end{array}$ \\
\hline Iowa Metal Spinners & - Responded by stating “requirements do not fit capabilities." \\
\hline PMF & - PMF focuses on three-roller flow-forming, not spin-forming. \\
\hline
\end{tabular}

\begin{tabular}{|c|c|c|c|c|c|c|c|}
\hline \multicolumn{8}{|c|}{$\begin{array}{l}\text { Table } 2 \text { Composition of the Annealed 21-6-9 ESR Stainless Steel } \\
\text { (used in Development } 1 \text { and 2) }\end{array}$} \\
\hline \multicolumn{8}{|c|}{ Chemical Analysis (weight percent) } \\
\hline $19.3 \% \mathrm{Cr}$ & \multicolumn{2}{|c|}{$7.3 \% \mathrm{Ni}$} & $9.35 \% \mathrm{Mn}$ & $.475 \% \mathrm{Si}$ & \multicolumn{2}{|c|}{$.272 \% \mathrm{~N}$} & $.0355 \%$ C \\
\hline $.0115 \% \mathrm{Al}$ & \multicolumn{2}{|c|}{$.0014 \%$ O } & $.0016 \% \mathrm{~S}$ & $.015 \% \mathrm{P}$ & \multicolumn{2}{|c|}{ balance Fe } & \\
\hline \multicolumn{8}{|c|}{ Sourcing Information } \\
\hline \multicolumn{2}{|c|}{ KCP Specification: } & \multicolumn{2}{|c|}{ 9855242-01-813-Z } & \multicolumn{2}{|c|}{$\begin{array}{c}\text { Rocky Flats } \\
\text { Specification: }\end{array}$} & \multicolumn{2}{|c|}{ P-14073-L } \\
\hline \multicolumn{2}{|c|}{$\begin{array}{r}\text { Material Control } \\
\text { Number: }\end{array}$} & \multicolumn{2}{|c|}{115831} & \multicolumn{2}{|c|}{$\begin{array}{r}\text { Date Received (by } \\
\text { Rocky Flats): }\end{array}$} & \multicolumn{2}{|c|}{$06 / 07 / 1990$} \\
\hline \multicolumn{2}{|c|}{ PO Number: } & \multicolumn{2}{|c|}{ WR-31799 } & \multicolumn{2}{|c|}{ Heat No: } & \multicolumn{2}{|c|}{ 433R6-1 } \\
\hline \multicolumn{2}{|c|}{ Producer: } & \multicolumn{2}{|c|}{ G.O. Carlson } & \multicolumn{2}{|c|}{ Grain Size: } & \multicolumn{2}{|c|}{ ASTM 5 to 6} \\
\hline \multicolumn{2}{|c|}{ Inclusion Rating: } & \multicolumn{2}{|c|}{$\begin{array}{l}1 \text { to } 11 / 2 \mathrm{D} \text { thin } 1 / 2 \mathrm{D} \\
\text { heavy }\end{array}$} & \multicolumn{2}{|c|}{ Ferrite Distribution: } & \multicolumn{2}{|c|}{$\begin{array}{l}.5 \text { to } 1.5 \mathrm{C} \text { thin and } 1 \\
\mathrm{C} \text { heavy }\end{array}$} \\
\hline \multicolumn{2}{|c|}{ Plate Size: } & \multicolumn{2}{|c|}{$.625 ” \times 26 ” \times 40 ”$} & & & & \\
\hline
\end{tabular}


Table 3 Composition of Annealed Vanadium (ppm)

\begin{tabular}{|c|c|c|c|c|c|c|c|}
\hline \multicolumn{5}{|c|}{ Experimental Material Analysis* } & \multicolumn{3}{|c|}{ Comparison to Other Vanadium } \\
\hline & $\begin{array}{l}\text { ATI Wah } \\
\text { Chang } \\
\text { Top }\end{array}$ & $\begin{array}{l}\text { ATI Wah } \\
\text { Chang } \\
\text { Middle }\end{array}$ & $\begin{array}{l}\text { ATI Wah } \\
\text { Chang } \\
\text { Bottom }\end{array}$ & $\begin{array}{c}\text { Los } \\
\text { Alamos } \\
\text { Nat'l Lab }\end{array}$ & $\begin{array}{l}\text { Ingot in } \\
\text { KCP } \\
\text { Stores** }\end{array}$ & $\begin{array}{l}\text { ATI Wah } \\
\text { Chang } \\
\text { Max }\end{array}$ & $\begin{array}{c}\text { ATI Wah } \\
\text { Chang } \\
\text { Typical }\end{array}$ \\
\hline $\mathrm{C}$ & 47 & 69 & 58 & 90 & 100 & 200 & 62 \\
\hline $\mathrm{H}$ & $<3$ & $<3$ & $<3$ & 8 & 10 & 10 & $<3$ \\
\hline $\mathrm{N}$ & 68 & 88 & 84 & 70 & 200 & 175 & 77 \\
\hline $\mathrm{O}$ & 260 & 420 & 190 & 170 & 500 & 300 & 170 \\
\hline $\mathrm{S}$ & $<10$ & $<10$ & $<10$ & 5 & 0 & & \\
\hline $\mathrm{Al}$ & 310 & 370 & 180 & 145 & 300 & 400 & 203 \\
\hline $\mathrm{Si}$ & 92 & 120 & 94 & 110 & $<1000$ & 500 & 197 \\
\hline $\mathrm{Fe}$ & $<200$ & $<200$ & $<200$ & 72 & & 200 & $<50$ \\
\hline $\mathrm{Ni}$ & $<50$ & $<50$ & $<50$ & 6 & & 50 & $<50$ \\
\hline $\mathrm{Cr}$ & $<50$ & $<50$ & $<50$ & 2 & & 50 & $<50$ \\
\hline $\mathrm{Fe}+\mathrm{Ni}+\mathrm{Cr}$ & & & & 80 & 60 & & \\
\hline $\mathrm{Nb}$ & $<100$ & $<100$ & $<100$ & 1 & & 100 & $<100$ \\
\hline Mo & $<50$ & $<50$ & $<50$ & 40 & & 500 & $<50$ \\
\hline $\mathrm{Ta}$ & $<100$ & $<100$ & $<100$ & 0 & & 500 & $<100$ \\
\hline $\mathrm{Nb}+\mathrm{Mo}+\mathrm{Ta}$ & & & & 41 & 160 & & \\
\hline $\mathrm{Ti}$ & $<50$ & $<50$ & $<50$ & 3 & & & \\
\hline $\mathrm{Zr}$ & $<50$ & $<50$ & $<50$ & 1 & & 500 & $<50$ \\
\hline $\mathrm{Hf}$ & $<100$ & $<100$ & $<100$ & 0 & & 100 & $<100$ \\
\hline $\mathrm{Ti}+\mathrm{Zr}+\mathrm{Hf}$ & & & & 4 & 30 & & \\
\hline $\mathrm{P}$ & $<30$ & $<30$ & $<30$ & 0 & 70 & & \\
\hline $\mathrm{P}+\mathrm{S}$ & & & & 5 & & & \\
\hline B & $<1$ & $<1$ & $<1$ & 0 & $<300$ & & \\
\hline U & $<1$ & $<1$ & $<1$ & 19 & $<100$ & & \\
\hline W & $<30$ & $<30$ & $<30$ & 3 & & & \\
\hline $\mathrm{Cu}$ & $<50$ & $<50$ & $<50$ & 230 & & 50 & $<50$ \\
\hline Sn & $<100$ & $<100$ & $<100$ & & & 100 & $<100$ \\
\hline Co & $<50$ & $<50$ & $<50$ & & & 50 & $<50$ \\
\hline $\mathrm{Zn}$ & & & & 83 & & & \\
\hline V & balance & balance & balance & balance & $99.6 \%$ & balance & balance \\
\hline $\begin{array}{l}\text { *Material ce } \\
\text { for } 62 \text { lbs tot } \\
\text { **Data are } \mathrm{f} \\
\text { totaling } 2455 \\
\text { manufacture }\end{array}$ & $\begin{array}{l}\text { tified } 03 / 21 \\
\text { l from heat } \\
\text { om lot } 8204 \\
\text { lbs, receive }\end{array}$ & $\begin{array}{l}8 \text { for PO: } 1 \\
\text { o: } 835949 \\
\text { B, KCP s } \\
\text { 10/18/199 }\end{array}$ & $\begin{array}{l}15860 \text {, sa } \\
\text { batch no } \\
\text { cification } \\
\text { on PO H4 }\end{array}$ & $\begin{array}{l}\text { es order no: } \\
\text { FAB-2049 } \\
587801, \mathrm{M} \\
0164-003-0\end{array}$ & $\begin{array}{l}137457 . \mathrm{F} \\
5 . \\
\text { SN } 200335 \\
2 \text { from Ka }\end{array}$ & $\begin{array}{l}\text { ve pieces we } \\
\text { originally } 5 \\
\text { ser-Hill for }\end{array}$ & $\begin{array}{l}\text { re ordered } \\
\text { bars } \\
\text { J.S. DOE, }\end{array}$ \\
\hline
\end{tabular}




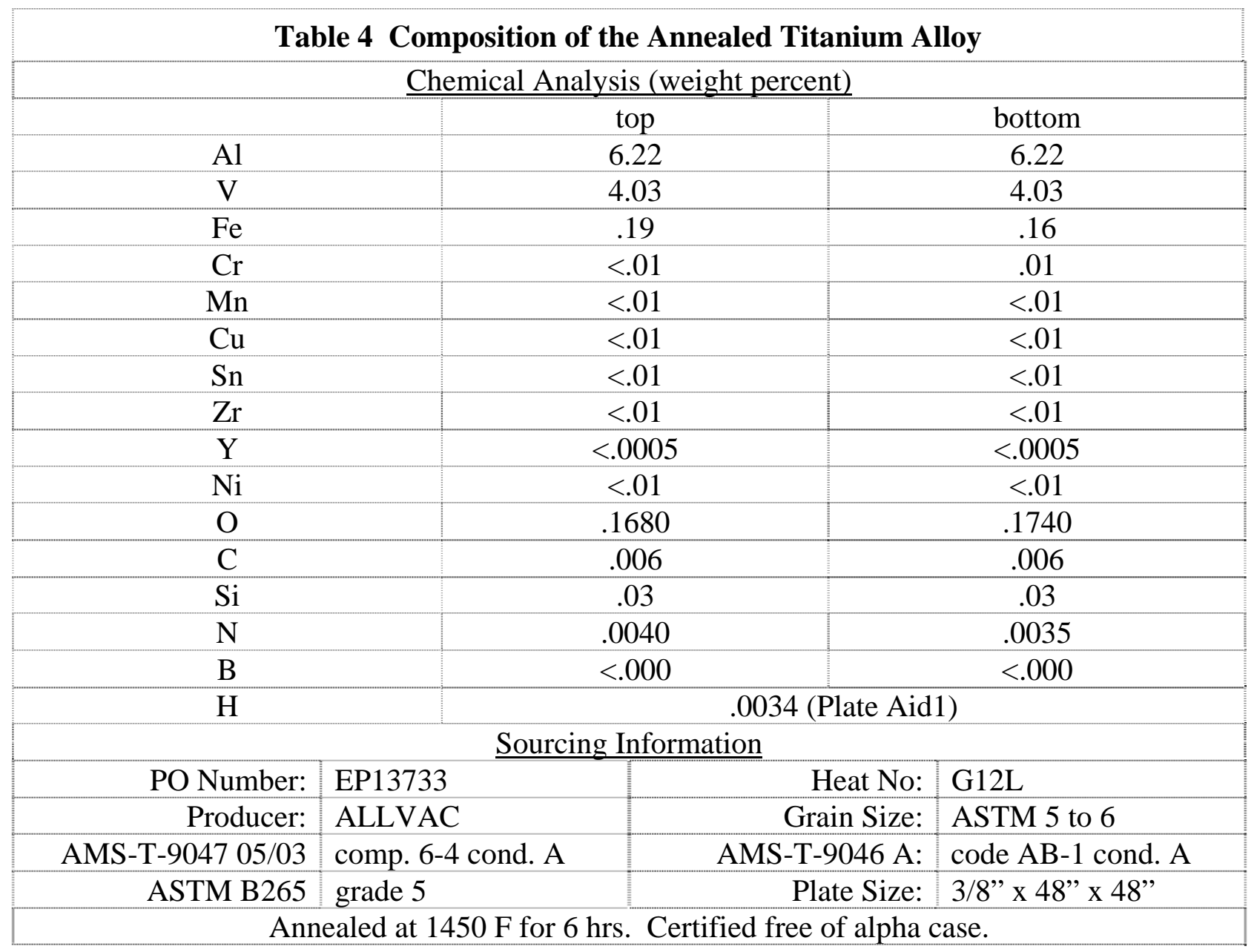

The development work took place at Forgitron in Camden, SC, where Hess had subcontracted the use of spin-forming equipment. KCP engineers directed, observed, and recorded the development process. This project also drew on the outside expertise available through Hess engineers, the Forgitron plant manager, and an RMF consultant (by teleconference). Table 5 gives the sizes of the starting circular plates of annealed raw material. Figure 1 shows the four materials as preformed and ready to be spin-formed. The previous report, KCP-613-8483, contains more information about the pre-form geometry. Copper was formed first, then 21-6-9 stainless steel, then pure vanadium, and finally the titanium alloy was heated and spin-formed. The team attempted to change only one factor at a time to simplify the interpretation of the effects of each parameter.

\begin{tabular}{|c|c|c|c|l|}
\hline \multicolumn{4}{|c|}{ Table 5 Dimensions of Starting Circular Plates } \\
\hline Material & Quantity & $\begin{array}{c}\text { Diameter } \\
\text { (inches) }\end{array}$ & $\begin{array}{c}\text { Thickness } \\
\text { (inches) }\end{array}$ & Comments: \\
\hline Copper & 5 & 12.5 & $.325 \pm .005$ & \\
\hline 21-6-9 Stainless & 10 & 12.25 & $.325 \pm .005$ & \\
\hline 21-6-9 Stainless & 5 & & $.325 \underline{.005}$ & Edges re-machined to remove notches \\
\hline Vanadium & 5 & 12.6 & $.446 \pm .012$ & \\
\hline Ti-6-4 & 5 & 12.25 & $.325 \pm .005$ & Notched and Laser Marked \\
\hline
\end{tabular}




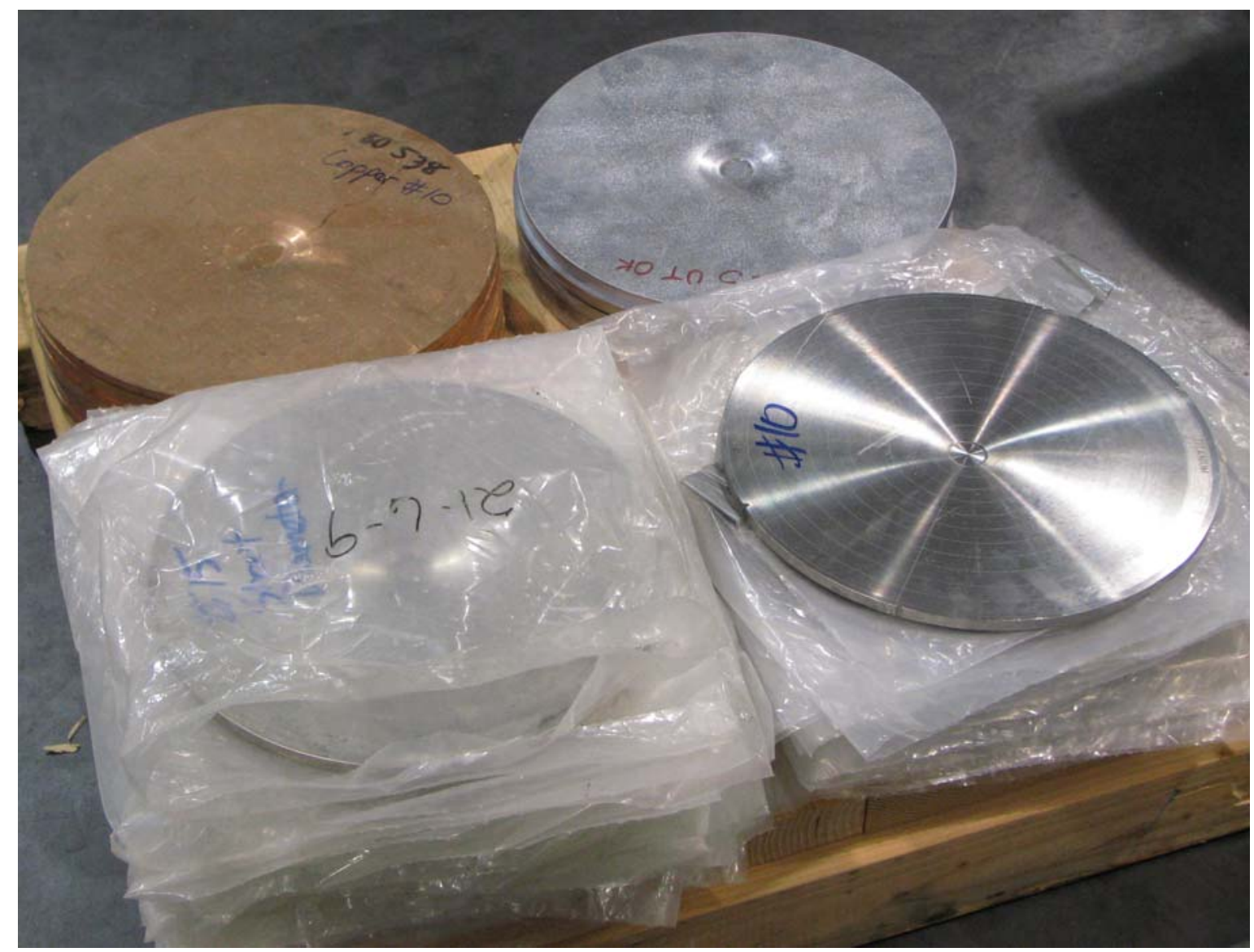

Figure 1 Pre-forms of the four materials: copper (upper left), vanadium (upper right), 21-6-9 stainless (lower left), titanium alloy (lower right).

\section{$\underline{\text { Pure Copper (C11000 ETP) }}$}

The first copper part (Development 2 part 1, D2P1) formed a large crack during pass four of nine, indicating that copper work hardens too much for a high number of passes. A single pass was used on D2P2, which cracked circumferentially in a similar fashion to Development 1 part number four (D1P4). Circumferential cracking is a typical spin-forming failure mode due to high "radial" tensile stresses, and can be a sign of too high "spinning ratio" (Ref 2).

Equation $1 \quad$ Spinning Ratio $=\frac{\text { Blank Diameter }}{\text { Mandrel Diameter }}$

A high spinning ratio means that the process is trying to take a large diameter blank and force it to form down to a small mandrel. Since the spinning ratio could not be changed, the team sought other means to eliminate the cracking. A recommendation was made to dial down the RPMs, asserting that lower RPMs result in "more bending and less thinning.” Technically speaking, reducing the RPMs likely increased the tangential component of force relative to the axial and radial components of force (Ref 3). It was determined that a low "feed ratio" caused excessive 
material flow outward, over-thinning of the wall, and ultimately this circumferential cracking (Ref 2).

Equation $2 \quad$ Feed Ratio $(\mathrm{mm} /$ rotation $)=\frac{\text { Roller Feed Rate }(\mathrm{mm} / \mathrm{min})}{\text { Spindle Speed }(R P M)}$

With a roller feed rate of $800 \mathrm{~mm} / \mathrm{min}$, reducing the spindle speed from $600 \mathrm{rpm}$ to $300 \mathrm{rpm}$ changed the feed ratio from $1.3 \mathrm{~mm} /$ rotation to $2.6 \mathrm{~mm} /$ rotation. This change eliminated the circumferential cracking for D2P3 and D2P4; however, a vertical (radial) crack of about 1" length formed in these parts. According to another researcher, decreasing the mandrel speed should have worsened the surface finish (Slater's studies of 70/30 brass); however in our study of ETP copper, no reduction in quality of surface finish was observed (Ref 4).

Radial cracks like those that occurred in D2P3 and D2P4 are another typical spin-forming failure, sometimes mitigated by increasing the number of spin-forming passes (Ref 2). On the other hand, beveling the edges to reduce the imposed stress at the periphery, was also recommended. Figure 2 demonstrates the value of beveling the edges to remove the corners to reduce the stress intensity and likelihood of crack formation. With beveled edges and two passes, copper part D2P5 was a success. Because two factors were varied from D2P4 to D2P5, D2P6 was run without beveled edges and with two passes. D2P6 resulted in multiple large cracks, implying that two passes did not help, but beveled edges did help to reduce cracking.
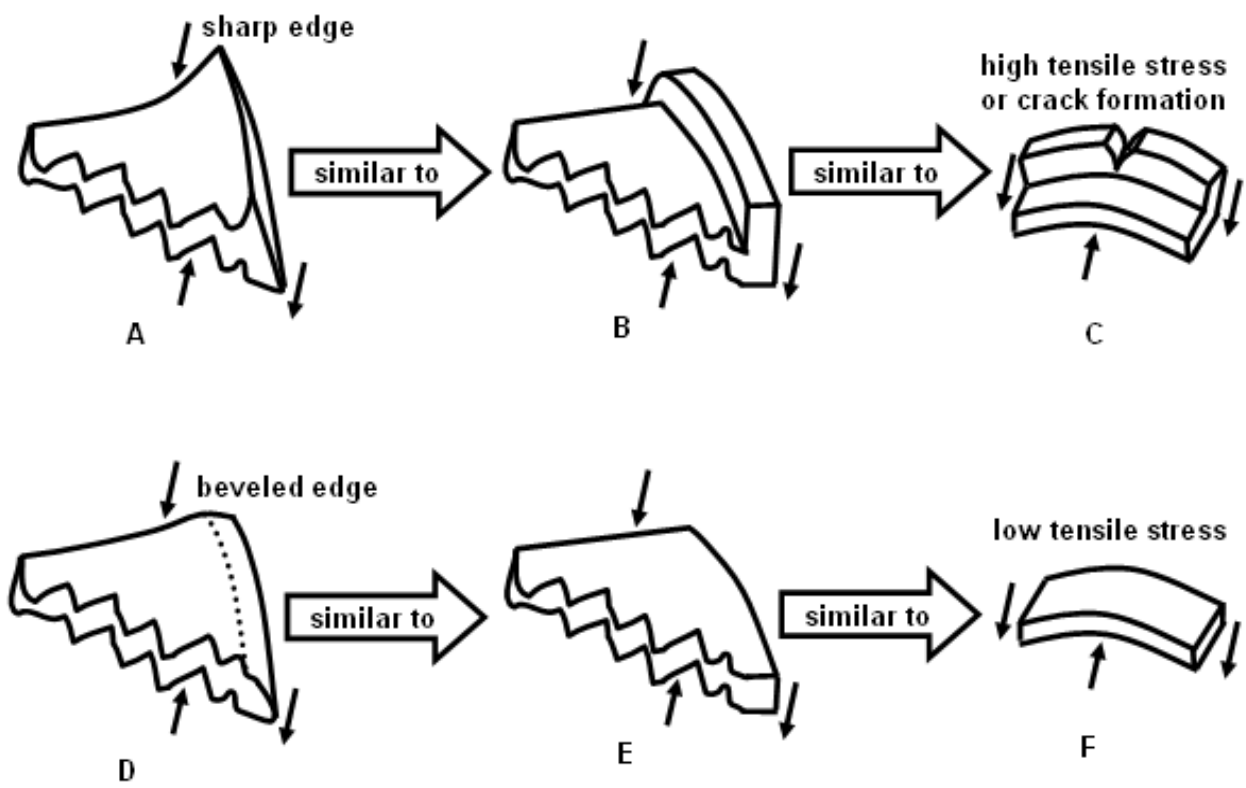

Figure 2 Schematic showing the value of beveling the edges of the preform material. Arrows point out the imposed forces during the spinforming process. A, B, and C show that sharp edges lead to higher stress at the extremities, causing cracking when the stress exceeds the fracture strength of the material. D, E, and F show that beveled edges lead to lower stress and reduced risk of cracking. 
Hess Industries, recalling their experience from Development 1, had machined the preforms to remove the notches (created by Honeywell for measurement purposes) and give them a nice, smooth surface finish on the edge (minimizing potential sites for crack initiation). Parts were run with a single pass program and coolant and at the same feed rate and RPM as copper (800 $\mathrm{mm} / \mathrm{min}$ and $300 \mathrm{rpm}$ ). Even though the edges were not beveled, D2P7-D2P12 resulted in good surface finish and no circumferential cracking or radial edge cracking. With this success, the process was perfected so that each 21-6-9 part could be run in an approximately 3-minute cycle time.

\section{$\underline{\text { Pure Vanadium }}$}

Fortunately, ATI Wah Chang manufactured the vanadium plates with a relatively smooth surface finish, which helped prevent cracking. The low deformation pressure and high ductility of vanadium also made it simpler to spin-form. The first vanadium part, D2P13 was run with a single pass and coolant. The surface resulted in a scaly appearance. A large outer flange remained for all vanadium parts due to the larger diameter of the preforms.

The second vanadium part, D2P14 was run with a single pass, without coolant. The material got too hot, emitted sparks, and stuck to the rollers, leaving a scaly surface. D2P14 was also poorly centered, leading to a non-symmetric final appearance. A 21-6-9 stainless part was run between each remaining vanadium part to clean any attached vanadium from the rollers.

The third vanadium part D2P16 was run with coolant and two passes, which lessened the severity of the surface scale. Subsequent vanadium parts, D2P18 and D2P20, were run with four and nine passes, respectively. The surface finish successively improved with more passes. D2P20 looked quite smooth, with nine passes. However, with a tailstock pressure of 45,000 lbs, the tailstock depression increased with increasing passes. This problem could likely be solved by simply reducing the tailstock pressure for soft materials such as vanadium.

If vanadium parts run with 1, 2, 4, and 9 passes are compared, it is also clear that the edge shape progresses from a flat appearance (with one pass) to a "creased" appearance (with nine passes). This is evidence that an increase in the number of passes results in more surface deformation, less residual tensile stress on the surface, and therefore less surface cracking. Slater found in his research that surface finish worsened as cone angle decreased as shown in Figure 3 (Ref 3). Accordingly, the spun hemispheres showed better surface finish near the beginning of the cycle where the cone angle was high and worse surface finish as the angle decreased. Slater also observed that an increase in mandrel speed improved surface finish (Ref 4). Instead, in KCP tests the number of passes was increased to improve surface finish for both vanadium and aluminum (from Development 1). 


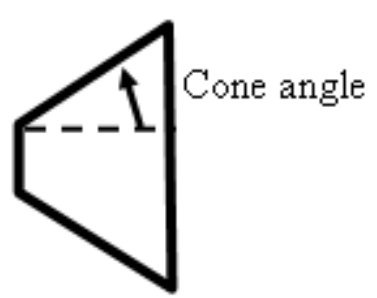

Large angle

Easier to spin

A

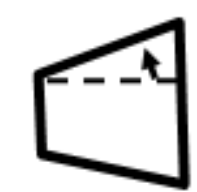

Small angle

More difficult to spin

B

Figure 3 The cone angle of the mandrel affects the surface finish in spin-forming. Larger cone angle, as shown in A leads to smoother surface, and smaller cone angle as shown in B leads to rougher surface.

\section{Titanium Alloy}

The first titanium alloy part (D2P22) was run with coolant, a single pass, and no heat input. Due to lack of formability, D2P22 failed even before the spin-form roller neared the $45^{\circ}$ cone angle. The crack closely followed the laser-mark impressions except under the position of the rollers, and in one location where the crack jumped from one laser mark to another. Also, even at the early stage of failure for D2P22, non-uniform deformation is visible at the extremities where the notches had been ground off.

After clamping the preform into the mandrel, D2P23 was spun and heated to over $1150 \mathrm{~F}$ by acetylene torch over a period of about 8-10 minutes. As the single pass program formed the part, it tore in a circumferential fashion as it moved past the $45^{\circ}$ location. Subsequent vertical tears occurred in what appeared to be the locations of the ground-off notches. In the video recording, a thin yellow line was visible a little bit ahead of the roller, implying a location of intense plastic deformation and heating due to internal friction. A similar "hot" line was also visible ahead of the roller in D2P24 and D2P25, although the color was not as bright.

D2P24 was spun and heated to 700-950 F by both propane and acetylene flames. During the single-pass operation, two cracks formed at the ground-off notch locations, and these cracks deformed into laps. Non-uniform deformation is visible in the entire part, seemingly due to the ground-off notch locations.

D2P25 was spun and heated to 500-750 F by acetylene, and formed with a single-pass program. The operation was aborted because the tailstock fractured and the machine began to wobble. The tailstock had a cylindrical crack in the depression, following the zone of highest stress concentration. Although the process was aborted, the non-uniform deformation in the titanium was already quite visible due to the locations of the ground-off notches. 
Development 1 and Development 2 were not pure tests to determine the shear spinnability of materials as proposed by Kegg (Ref 5). Although a hemispherical mandrel was used-which varied the semi-angle (cone angle) from $90^{\circ}$ to $0^{\circ}$ - the sine law was not followed. Figure 4 shows illustrations of the sine law for true shear-forming. The sine law states that final thickness, $t_{f}$, equals initial thickness, $t_{i}$, multiplied by the sine of the semi angle, $\alpha$ (see Figure 4b).

Equation $3 \quad t_{\mathrm{f}}=\mathrm{t}_{\mathrm{i}} \sin \alpha \quad$ (Sine Law Equation)

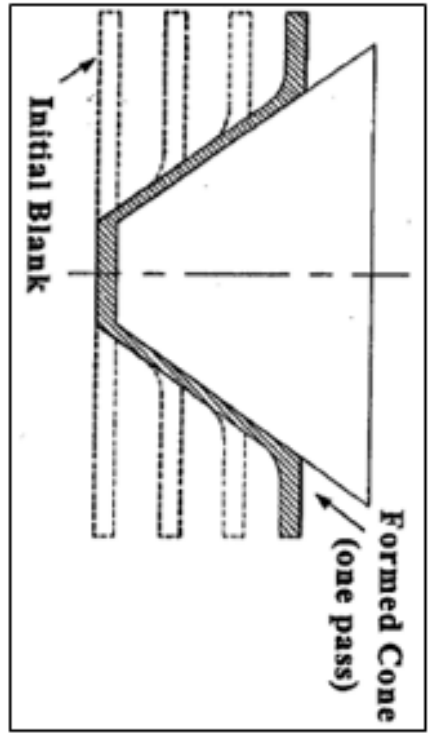

A

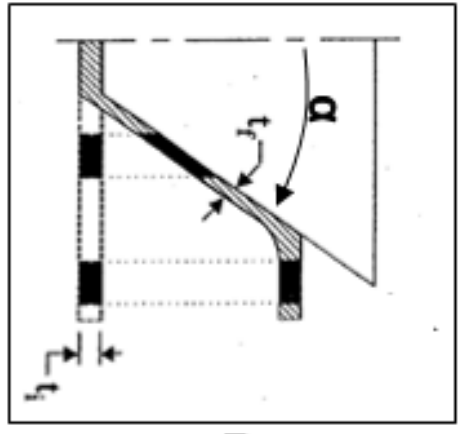

B

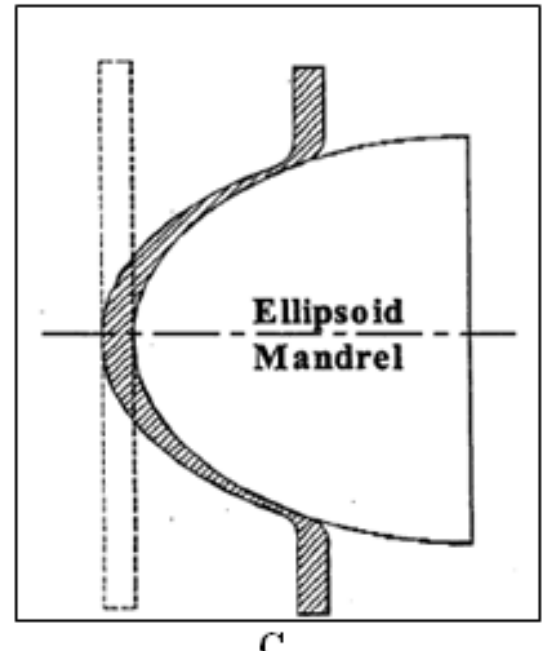

C

Figure 4 Illustrations of the sine law (true shear-forming). A) Single pass, idealized true shear-forming. B) Deformation elements according to the sine law. C) Shear spinnability test with a continually decreasing cone angle, to find the limit of the shear ductility of the material (Ref 6).

If the sine law had been strictly followed in our tests, every material would have cracked prior to forming at $0^{\circ}$, because the stretching would have been infinite. Instead, what is called "underspin-forging" or "underspinning" was performed in our tests, where material is "sucked in" from the remaining flange. Underspinning was also evident since the starting blank was about 12 inches in diameter and the final part was about 8-10 inches in diameter. By contrast, an "overspin-forging" or "overspinning" condition would be evident if material was extruded by the roller to increase the size of the flange during spinning (Ref 7). What used to be labeled, "truespin-forging”, i.e., following the sine law equation, is also currently called "shear forming" (Ref 6). Although Development 1 and Development 2 were not pure shear forming operations following the sine law, our results with the various materials proved that acceptable parts may be spin-formed using a combination of spin-forming and shear-forming techniques, the specifics of which depend on the material in question. 


\section{Lessons Learned}

The following are some recommendations resulting from Development 2:

1. The surface finish of the preform is critical for any material; it must be smooth and free of laser marks, notches, defects, or non-uniformities.

2. If the part tends to form a circumferential crack at about the 45 degree location (as in Development 2, Part 2, D2P2), lowering the RPM, while maintaining the same feed rate may help to "increase bending and reduce thinning." This effect is similar to "Lesson Learned 6" from KCP-613-8483, in which Hess reported that faster feed rates improved the results in copper and aluminum.

3. If a part tends to form vertical cracks in the extreme edges (as in D2P3, D2P4, and D2P6), beveling the edges may help to lower the stress intensity, and ensure success. Reducing the number of passes may also benefit by not cold-working the edges, which would reduce ductility for the final stages and increase strength and stress intensity in the edges (as is seen in D2P6).

4. If an abundance of surface cracking is present as in D2P13, D2P14, D2P16, and $\mathrm{D} 2 \mathrm{P} 18$, increasing the number of passes (from one to nine) may help to reduce surface cracking by reducing surface stresses.

5. If material ductility is poor as in titanium alloy (D2P22), heat input may be required for deformation. When heat is applied, the surface finish must be very smooth, and the surface must be free of notches, laser marks, or defects to promote uniform deformation, uniform heating due to plastic deformation, and prevent failure in "hot spots."

6. Tailstock material selection is important. In Development 1 a D2 tool steel tailstock hardened to 58-62 HRC failed on the first 21-6-9 apparently because of the high stresses resulting from trying to use a single roller on .320 in. stainless steel. A tailstock was then made from pre-heat treated 27-32 HRC 4140 steel. This 4140 tailstock held up through single roller spinning of copper, aluminum, and tantalum2.5\%tungsten and double-roller spinning of tantalum-2.5\%tungsten, copper, vanadium, and about twenty stainless steel parts. After a crack formed in the inner radius, the 4140 tailstock was retired and replaced with one made from ETD 150 (similar to 4150) pre-heat treated to 30-35 HRC. This tailstock was used for the hotspin-forming of titanium alloy. The heating process exposed the tailstock to high temperatures, probably reducing the hardness and strength. The ETD 150 tailstock only endured through two hot titanium alloy runs before developing a circular crack in the inner radius similar to that of the 4140 tailstock. For room temperature spinforming 4140 and ETD 150 are probably sufficient, but for high temperature spinforming Ted Bush from Hess recommends a high temperature tool steel such as H13 for the tailstock.

The following are some "lessons learned" resulting from revisiting of Development 1 data (see report KCP-613-8483) with the added insight from Development 2:

1. For aluminum (Development 1 Consecutive Order Part 8, D1P8), just as in vanadium, a surface finish improvement was noted when increasing from one to nine passes. Similarly, when comparing D1P24 with D1P26 and D1P13, an increase from one to nine passes resulted in improved surface finish in tantalum-2.5\%tungsten.

2. 304L stainless steel (D1P27) demonstrates the effect of multiple passes on a material that cold-works quickly, resulting in cracking at the extremities.

3. Contrary to the Lessons Learned in KCP-613-8483, copper seemed to form just as well with two passes (D2P5) as with nine (D1P9 \& D1P10). 


\section{Future Work}

Three 21-6-9 stainless steel hemishells have been selected for the testing schedule shown in Figure 5. These 21-6-9 shells, as well as "as-spun” Ta-2.5\%W (D1P13), and pure vanadium hemishells will undergo ultrasonic testing, residual stress testing, metallography, hardness, and tensile testing. Figure 6 gives the metallographic (hardness) and tensile bar locations.

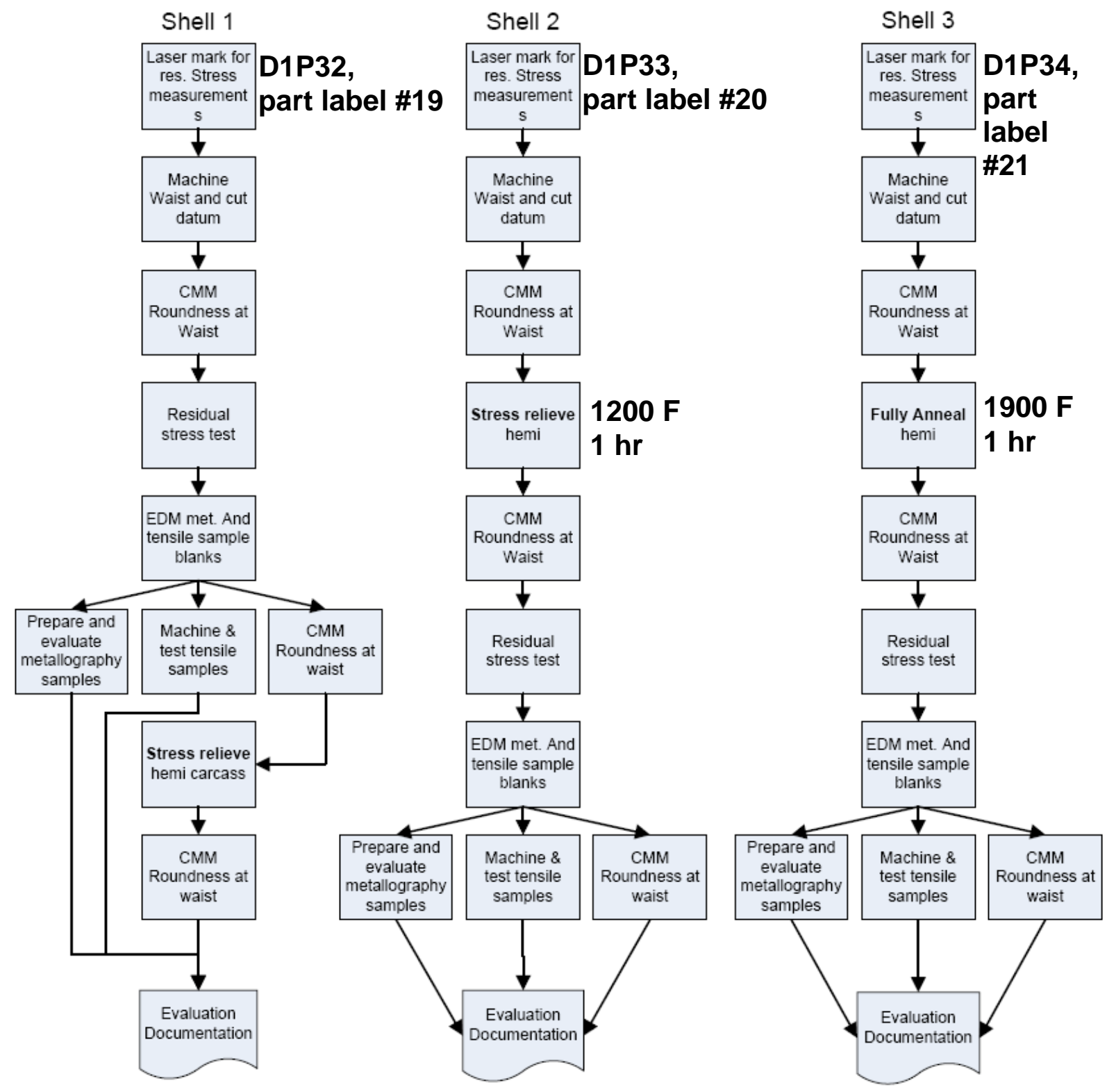

Figure $5 \quad$ Flowchart for testing of three 21-6-9 stainless steel hemishells. 


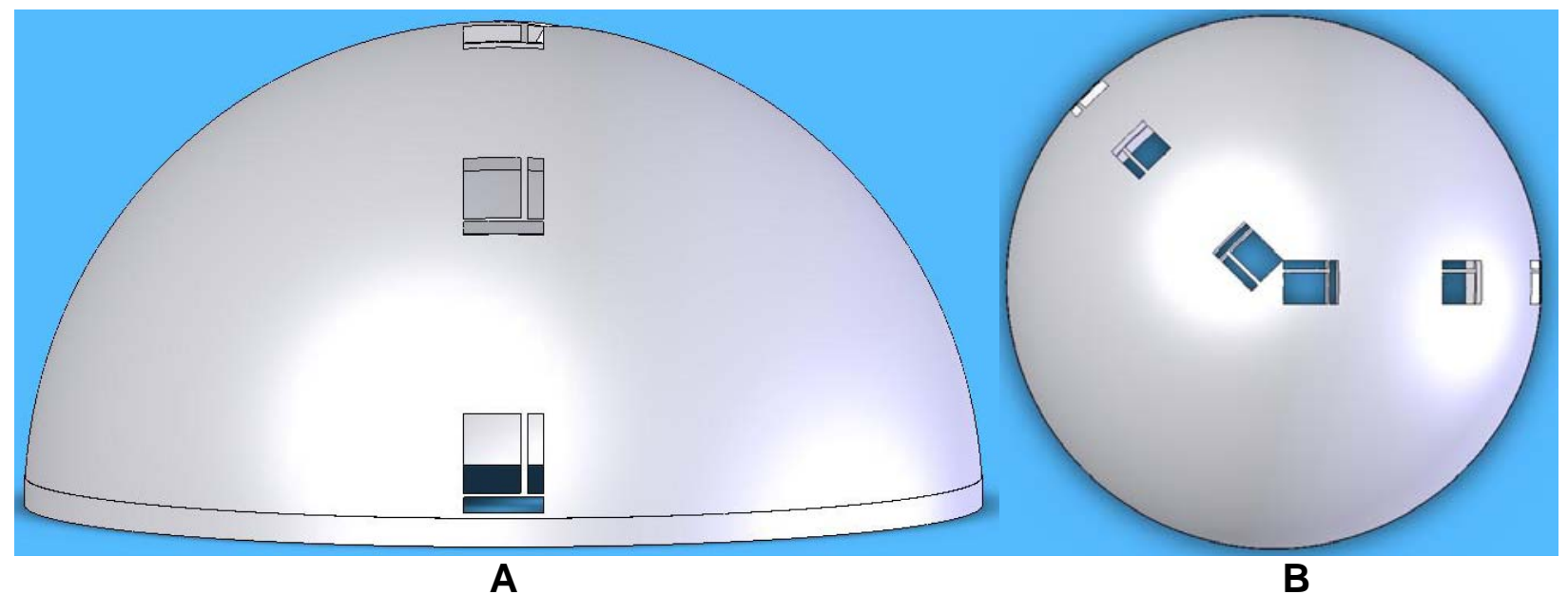

A

B

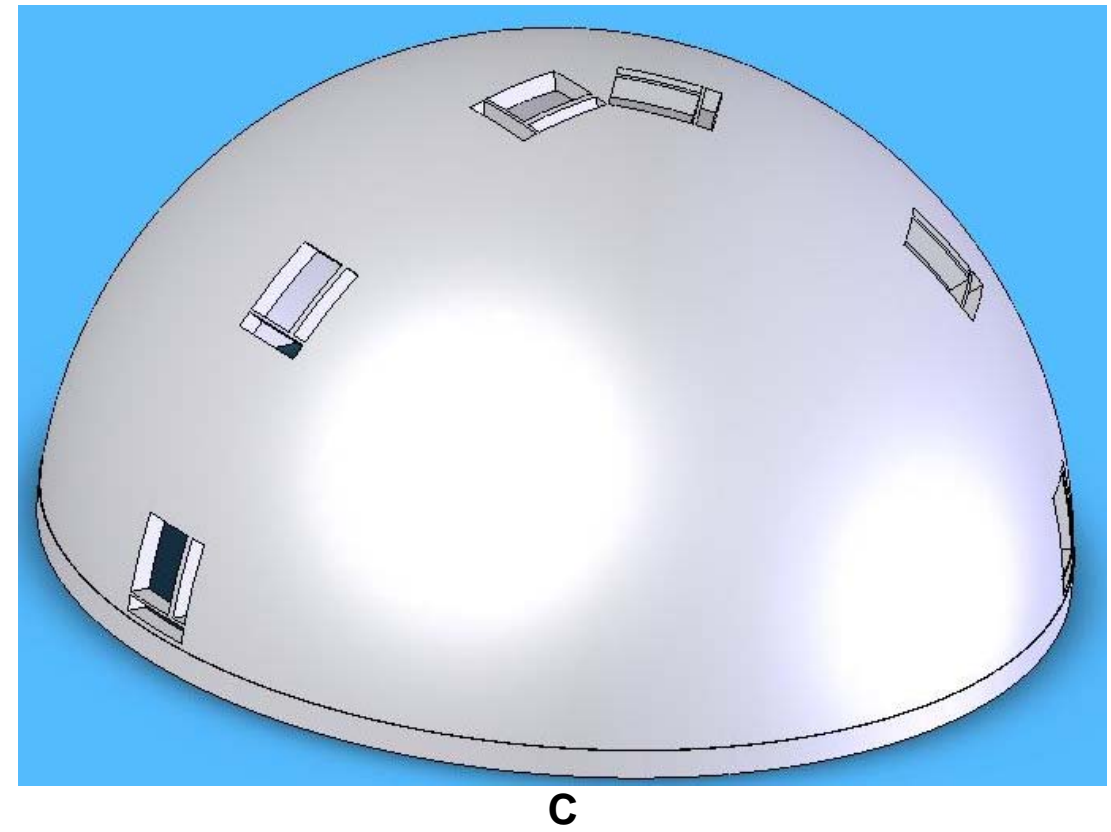

Figure 6 Locations of metallographic (hardness) and tensile samples for hemishells of 21-6-9 stainless steel, Ta-2.5\%W, and pure vanadium. Large rectangles represent metallographic and hardness samples. Slender rectangles are tensile bar locations. Side view is shown in A, top view in B, and trimetric in C. 


\section{References}

1. R. S. Henry, N. T. Switzner, Spin-Forming Project Report (Final Report). UNCLASSIFIED. FM\&T: KCP-613-8483, September 2008.

2. C. C. Wong, T. A. Dean, and J. Lin, "A Review of Spinning, Shear Forming and Flow Forming Processes.” International Journal of Machine Tools and Manufacture, Volume 43, 2003, pp. 1419-1435.

3. R. A. C. Slater, "Spin-Forging of Sheet Metal Cones having Various Cone Angles from 7030 Brass and Commercially Pure Aluminum.” Metal Forming Plasticity International Union of Theoretical and Applied Mechanics. Tutzing, Germany: August 28, 1978, pp 27-52.

4. R. A. C. Slater, "Effects of Mandrel Speed and Roller Feed Rate on the External Surface Finish During the Spin-Forging of 70/30 Brass Sheet Metal Cones.” $1^{\text {st }}$ International Conference on Rotary Metal-Working Processes. London, UK: November 20-22, 1979, pp 217-228.

5. R. L. Kegg, "A New Test Method for Determination of Spinnability of Metals.” Transactions of the American Society of Mechanical Engineers, Series B, Journal of Engineering for Industry, Volume 83, 1961, pp 119-124.

6. E. Hagan and J. Jeswiet, "A Review of Conventional and Modern Single-Point Sheet Metal Forming Methods.” Journal of Engineering Manufacture, Volume 217, Number. 2, 2003, pp 213-225.

7. R. A. C. Slater, "A Review of Analytical and Experimental Investigations of the SpinForging of Sheet Metal Cones." $1^{\text {st }}$ International Conference on Rotary Metal-Working Processes. London, UK: November 20-22, 1979, pp 33-60.

\section{Additional Resources}

1. M. W. Burnham, C. M. Edstrom, S. L. Bokan, "Development of Spin-formed Machining Blanks.” PFT-86-0006 (Rockwell International R\&D Report). Rockwell International, Rocky Flats Plant, P.O. Box 464, Golden, CO 80401, June 10, 1986.

2. W. G. Gates, “Spin Forming Development.” BID-A196 (Internal) or BDX-613-2709 (Topical Report on project 6985183). Bendix Kansas City Division, October 1981 (Internal) or May 1982 (Published).

3. W. G. Gates, "Spin Forming,” BDX-613-3346 (Topical Report on project 6985183). Allied Bendix Aerospace, September 1986.

4. W. G. Gates, “Spin Forming,” BDX-613-3689 (Topical Report). Bendix Allied Signal, March 1987.

5. A. Alcala Lambistos, "Introduction to the Spinning Techniques.” DENN, Industrias Puigjaner, s.a., Pintor Vila Cinca 30 - Pol. Ind. Can Humet de Dalt, 08213 POLINYA (Barcelona) Spain. Tel. 93-713-20-01 / Fax 93-713-11-25, email: denn@denn.es. 
Appendices 
Appendix A: Additional Data for Development 1 Materials (KCP-613-8483)

Table A1 Composition of the 6061 Aluminum From Development 1

\begin{tabular}{|c|c|c|c|c|c|c|c|}
\hline \multicolumn{8}{|c|}{ Chemical Analysis (weight percent) } \\
\hline $1.01 \mathrm{Mg}$ & \multicolumn{2}{|c|}{$.76 \mathrm{Si}$} & $.34 \mathrm{Cu}$ & $.19 \mathrm{Cr}$ & \multicolumn{2}{|c|}{$.52 \mathrm{Fe}$} & $.08 \mathrm{Zn}$ \\
\hline $.05 \mathrm{Mn}$ & \multicolumn{2}{|c|}{$.02 \mathrm{Ti}$} & $.01 \mathrm{~V}$ & .06 other & \multicolumn{2}{|c|}{ balance $\mathrm{Al}$} & \\
\hline \multicolumn{8}{|c|}{ Sourcing Information } \\
\hline \multicolumn{2}{|c|}{ PO Number: } & \multicolumn{2}{|c|}{ PC0142082 } & \multicolumn{2}{|c|}{ Heat No: } & \multicolumn{2}{|c|}{ 395228AO } \\
\hline \multicolumn{2}{|c|}{ Producer: } & \multicolumn{2}{|c|}{ Kaiser Aluminum } & \multicolumn{2}{|c|}{ Plate Size: } & \multicolumn{2}{|c|}{$3 / 8 ”$ x 48” x 48” } \\
\hline
\end{tabular}

Table A2 Composition of the 304L Stainless Steel From Development 1

\begin{tabular}{|c|c|c|c|c|c|c|c|}
\hline \multicolumn{8}{|c|}{ Chemical Analysis (weight percent) } \\
\hline $18.45 \% \mathrm{Cr}$ & \multicolumn{2}{|c|}{$11.6 \% \mathrm{Ni}$} & $1.9 \% \mathrm{Mn}$ & $.52 \% \mathrm{Si}$ & \multicolumn{2}{|c|}{$.0385 \% \mathrm{~N}$} & $.017 \% \mathrm{C}$ \\
\hline $.105 \% \mathrm{Mo}$ & \multicolumn{2}{|c|}{$.044 \%$ Co } & $.0015 \% \mathrm{~S}$ & $.024 \% \mathrm{P}$ & \multicolumn{2}{|c|}{ balance Fe } & \\
\hline \multicolumn{8}{|c|}{ Sourcing Information } \\
\hline \multicolumn{2}{|c|}{ KCP Specification: } & \multicolumn{2}{|c|}{$9851642-01-818-Z$} & \multicolumn{2}{|c|}{$\begin{array}{l}\text { Rocky Flats } \\
\text { Specification: }\end{array}$} & \multicolumn{2}{|c|}{$\mathrm{P}-12053-\mathrm{E}$} \\
\hline \multicolumn{2}{|c|}{$\begin{array}{r}\text { Material Control } \\
\text { Number: }\end{array}$} & \multicolumn{2}{|c|}{115636} & \multicolumn{2}{|c|}{$\begin{array}{l}\text { Date Received (by } \\
\text { Rocky Flats): }\end{array}$} & \multicolumn{2}{|c|}{ 07/17/1989 } \\
\hline \multicolumn{2}{|c|}{ PO Number: } & \multicolumn{2}{|c|}{ WR-58284 } & \multicolumn{2}{|c|}{ Heat No: } & \multicolumn{2}{|c|}{ 1C578-1B } \\
\hline \multicolumn{2}{|c|}{ Producer: } & \multicolumn{2}{|c|}{ G.O. Carlson } & \multicolumn{2}{|c|}{ Grain Size: } & \multicolumn{2}{|c|}{ ASTM 5} \\
\hline \multicolumn{2}{|c|}{ Inclusion Rating: } & \multicolumn{2}{|c|}{1 to $11 / 2 \mathrm{D}$ thin } & \multicolumn{2}{|c|}{ Ferrite Distribution: } & \multicolumn{2}{|c|}{$\begin{array}{l}\text { 1A thin to none } \\
\text { (string-3 }<0.5 \text { ) }\end{array}$} \\
\hline \multicolumn{2}{|c|}{ Plate Size: } & \multicolumn{2}{|c|}{$1.25 ” \times 26 ” \times 35 ”$} & & & & \\
\hline
\end{tabular}

\begin{tabular}{|c|c|c|c|c|c|c|c|}
\hline \multicolumn{8}{|c|}{ Table A3 Composition of Tantalum-2.5\%Tungsten From Development 1} \\
\hline \multicolumn{8}{|c|}{ Chemical Analysis } \\
\hline $97.47062 \% \mathrm{Ta}$ & \multicolumn{2}{|c|}{$2.52 \% \mathrm{~W}$} & $27.5 \mathrm{ppm} \mathrm{Nb}$ & $2.95 \mathrm{ppm}$ Mo & \multicolumn{2}{|c|}{$0.159 \mathrm{ppm} \mathrm{Fe}$} & $0.020 \mathrm{ppm} \mathrm{Si}$ \\
\hline $0.008 \mathrm{ppm} \mathrm{Ni}$ & \multicolumn{2}{|c|}{$0.002 \mathrm{ppm} \mathrm{Ti}$} & 25 ppm O & 19 ppm N & \multicolumn{2}{|c|}{ <10ppm C } & $<5 \mathrm{ppm} \mathrm{H}$ \\
\hline \multicolumn{8}{|c|}{ Sourcing Information } \\
\hline \multicolumn{2}{|c|}{ Producer: } & \multicolumn{2}{|l|}{ Cabot } & \multicolumn{2}{|c|}{ Cert. Number: } & \multicolumn{2}{|l|}{15136} \\
\hline \multicolumn{2}{|c|}{ Certification Date: } & \multicolumn{2}{|c|}{$10 / 11 / 2007$} & \multicolumn{2}{|c|}{ Purchase Order: } & \multicolumn{2}{|l|}{ EP13988 } \\
\hline \multicolumn{2}{|c|}{ Originating Lot: } & \multicolumn{2}{|c|}{279163} & \multicolumn{2}{|c|}{ Finished Lot: } & \multicolumn{2}{|l|}{301655} \\
\hline \multicolumn{2}{|c|}{ Temper: } & \multicolumn{2}{|c|}{ Annealed } & \multicolumn{2}{|c|}{ Anneal No.: } & \multicolumn{2}{|c|}{ 09287-2 \#8 } \\
\hline \multicolumn{2}{|c|}{ Flatness: } & \multicolumn{2}{|c|}{ Within $6 \% \max$} & \multicolumn{2}{|c|}{ Specification: } & \multicolumn{2}{|c|}{ ASTM B708, R05252 } \\
\hline \multicolumn{2}{|c|}{ ASTM grain size: } & \multicolumn{2}{|l|}{7.4} & \multicolumn{2}{|c|}{ Recrystallization \%: } & \multicolumn{2}{|l|}{$93.50 \%$} \\
\hline \multicolumn{2}{|c|}{ Dimensions: } & \multicolumn{6}{|c|}{0.326 ” thickness by 12.25 ” diameter } \\
\hline
\end{tabular}




\section{Appendix B: Scope of Work for Spin-Form Development Order 2}

\section{Scope of Work for Spin Forming Tool Fabrication and Development 2}

\section{A. REQUIREMENTS}

a. Seller must perform work on machine with the following characteristics.

i. Manufactured in the United States of America

ii. Computer numerical control (CNC)

iii. Enough power to spin 0.321 " thick stainless steel at room temperature (approximately $15 \mathrm{~K}$ pounds minimum X \& Z slide force)

iv. Coordinate programmable as opposed to playback programmable

v. Capable of hot spinning

vi. Two rollers

b. Seller must also be able to sell equipment of above description.

B. BUYER PROVIDED MATERIAL

a. Buyer will provide the following material for the spin forming development work:

i. 15 pieces of 12.25 "DIA x $.325+.005$ " thickness annealed and preformed Nitronic 40 (21-6-9 stainless steel)

ii. 5 pieces of 12.6 "DIA $x .446+.012$ " thickness pure vanadium

iii. 5 pieces of 12.5 "DIA x .325+.005" thickness annealed ETP copper

iv. 5 pieces of 12.25 "DIA $\times .325+.005$ " thickness Ti-6Al-4V (for hot-spinning)

V. Pre-form punch and die tooling

vi. Spin-form mandrel and tailstock tooling (drawings attached). The interfaces may be reconfigured as necessary.

C. SCOPE OF WORK
a. Develop appropriate CNC programs for spin-forming each material.

b. Honeywell associates shall be notified two weeks in advance of spin-forming so that they may be present during the operation.

c. Spin 5 parts of Nitronic 40 (21-6-9 stainless steel) with lubricant and a single pass program.

d. Spin 5 parts of pure vanadium with lubricant and an appropriate multiple pass program.

e. Spin 5 parts of ETP copper with lubricant and an appropriate multiple pass program.

f. Hot-spin 5 parts of Ti-6Al-4V with lubricant and an appropriate multiple pass program.

D. DELIVERABLES

a. Copy of most successful programs for each material

b. Copy of heating schedule for Ti-6AI-4V

c. All tooling (both tooling sent by Honeywell and possible additional tooling made by seller)

d. 5 spin-formed pieces of Nitronic 40 (21-6-9 stainless steel) regardless of condition plus leftover preformed plates

e. 5 spin-formed pieces of pure vanadium regardless of condition with at least one piece meeting dimensional requirements (as shown in attached drawing)

f. 5 spin-formed pieces of ETP copper regardless of condition

g. 5 hot-spin-formed pieces of Ti-6Al-4V regardless of condition

E. SCHEDULE

a. All activities shall be completed by August 30, 2008.

F. BUYER TECHNICAL SUPPORT CONTACTS

a. Seller shall contact the designated Buyer's representatives for all technical information and support activities. 


\section{Appendix C: Results of Spin-Form Development Order 2}

\section{August 26-27}

Note:

45,000 lb tailstock force

was used on all parts.
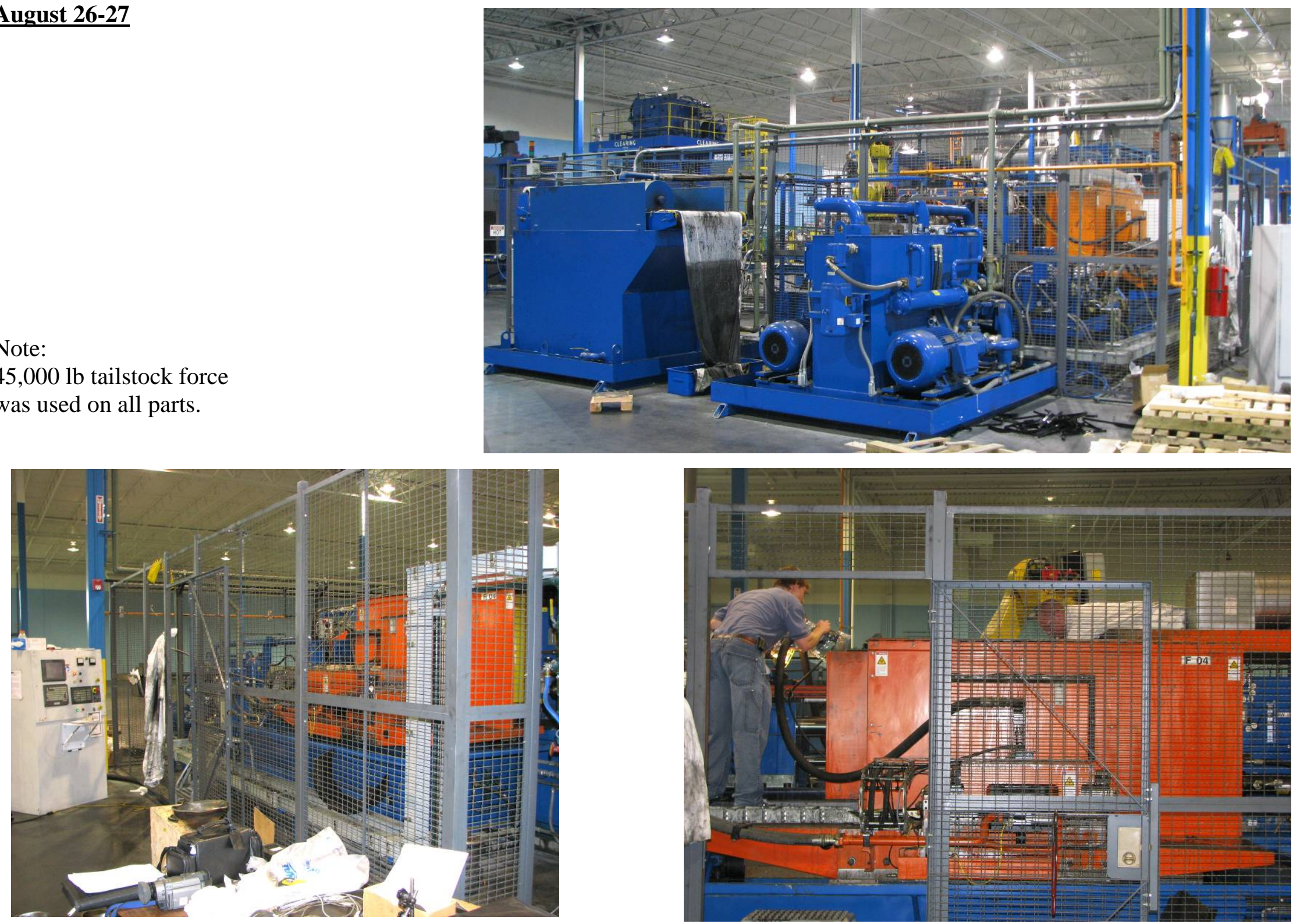


\section{Appendix C: Results of Spin-Form Development Order 2}

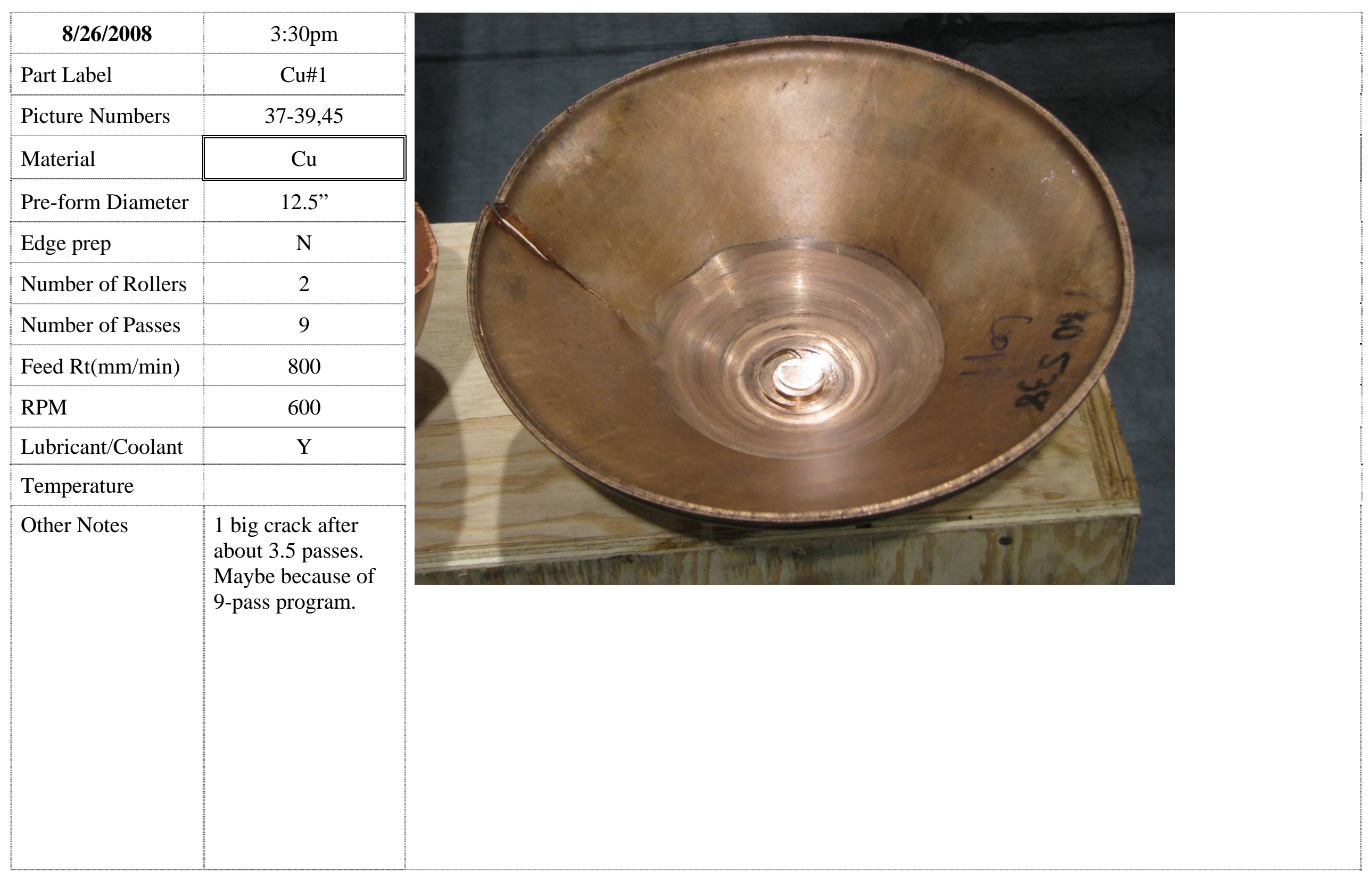


Appendix C: Results of Spin-Form Development Order 2

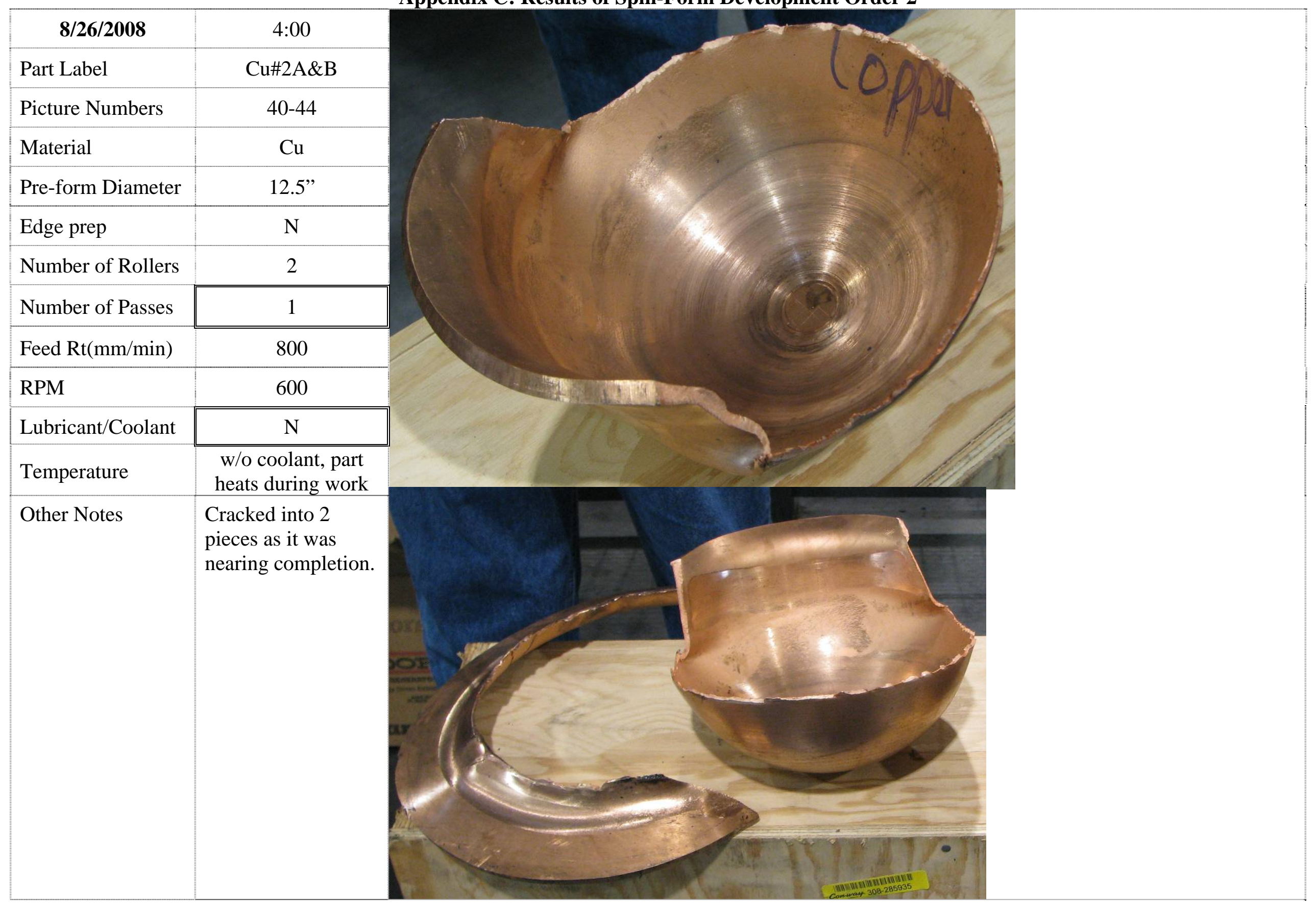




\section{Appendix C: Results of Spin-Form Development Order 2}

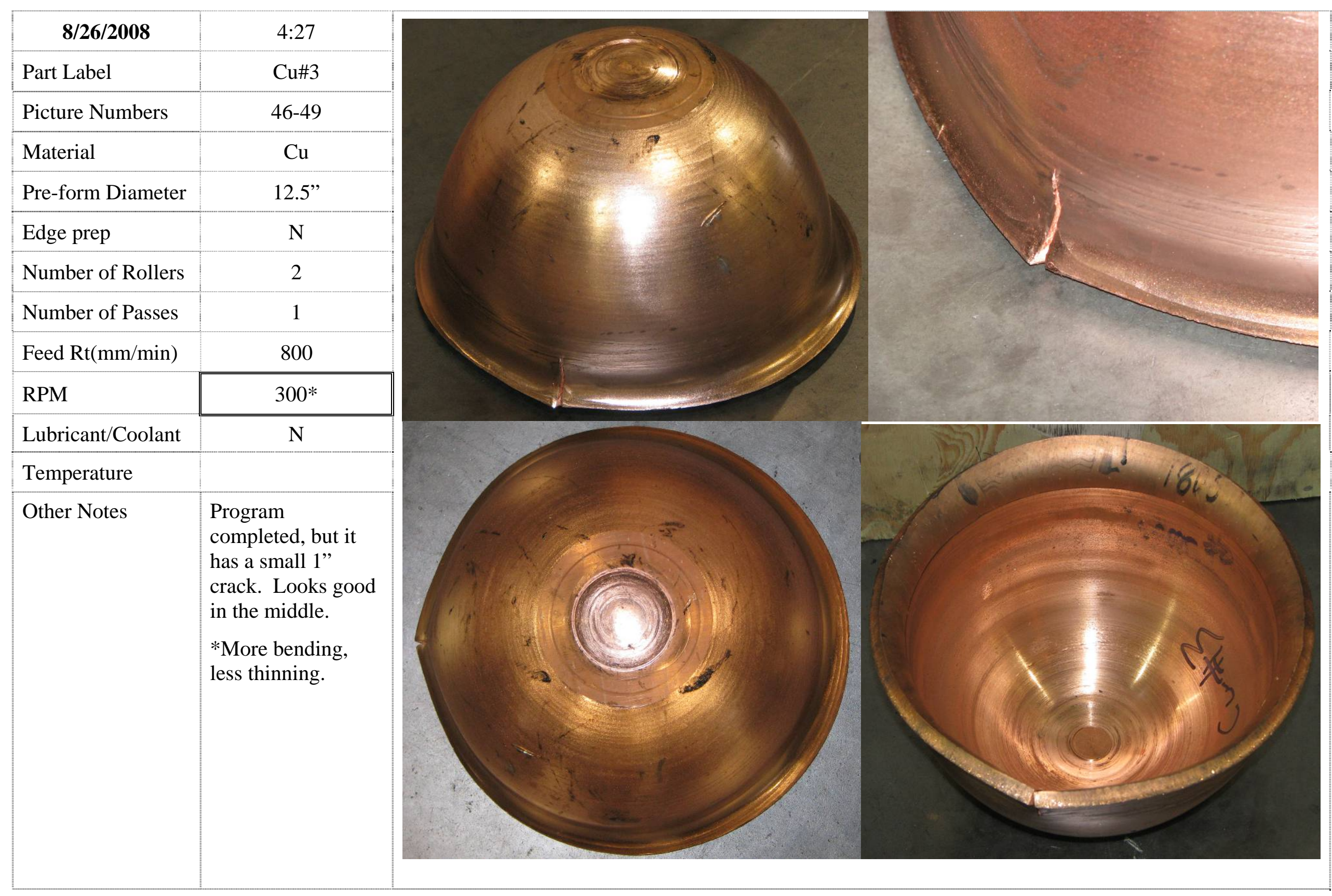


Appendix C: Results of Spin-Form Development Order 2

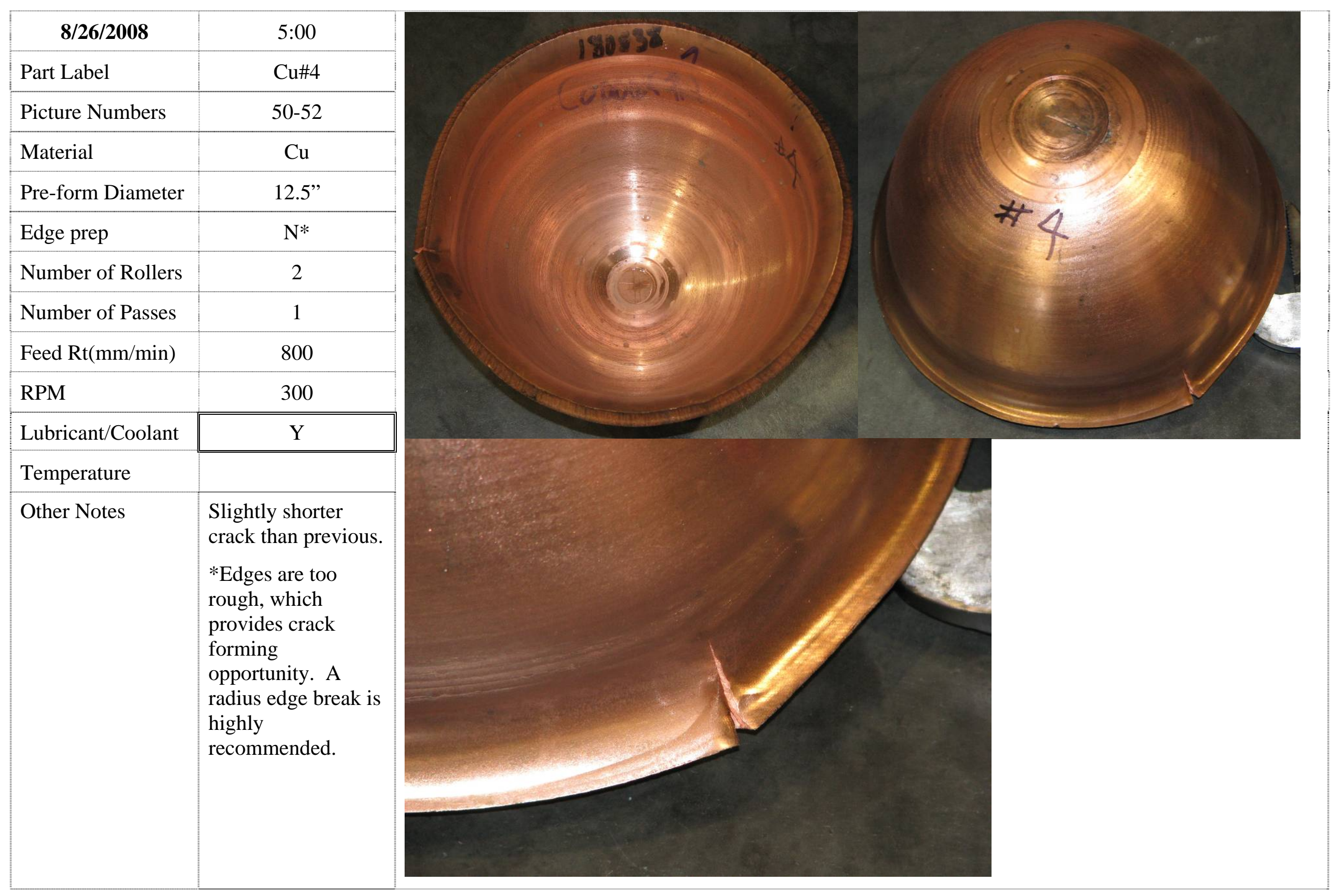




\section{Appendix C: Results of Spin-Form Development Order 2}

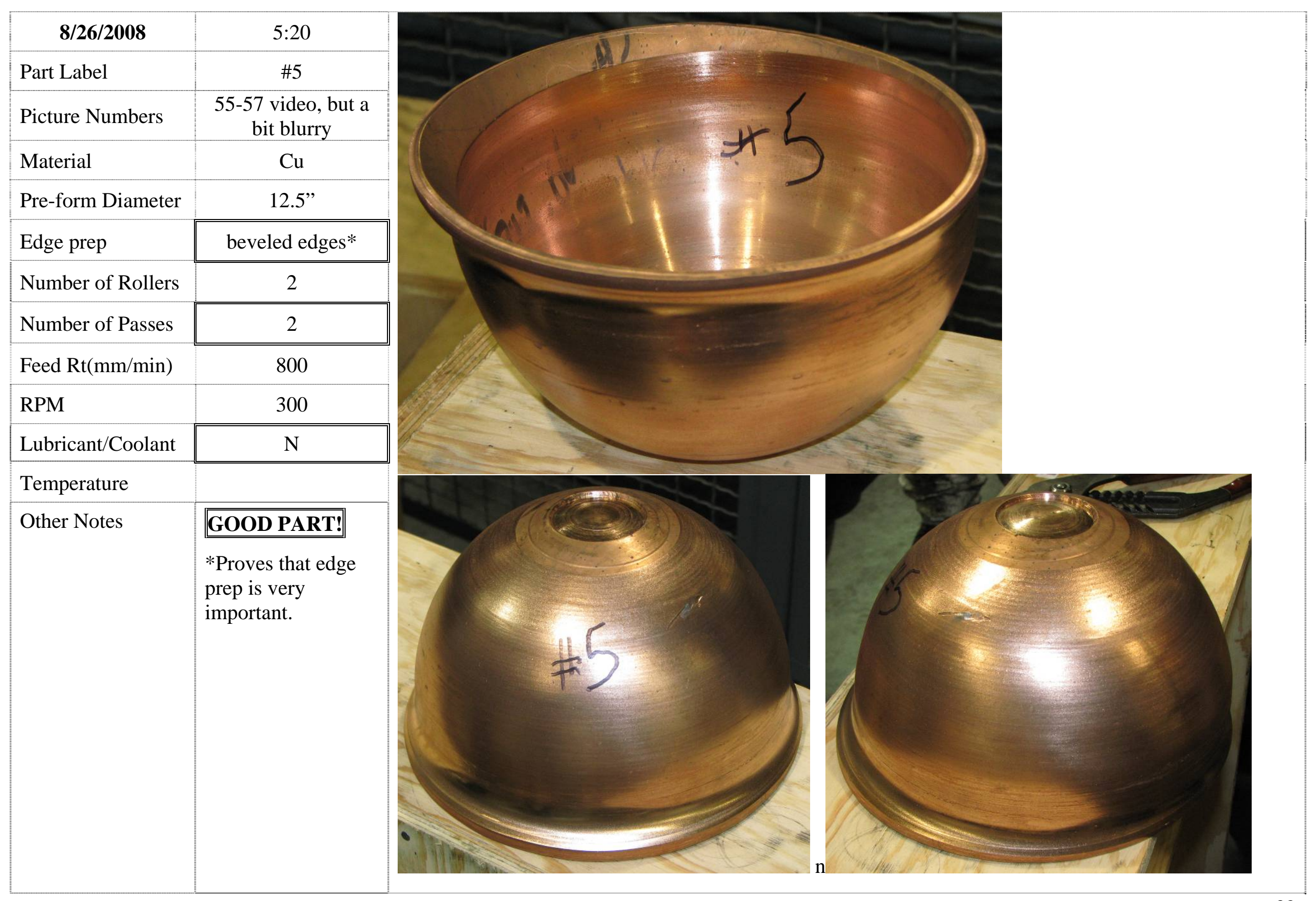




\section{Appendix C: Results of Spin-Form Development Order 2}

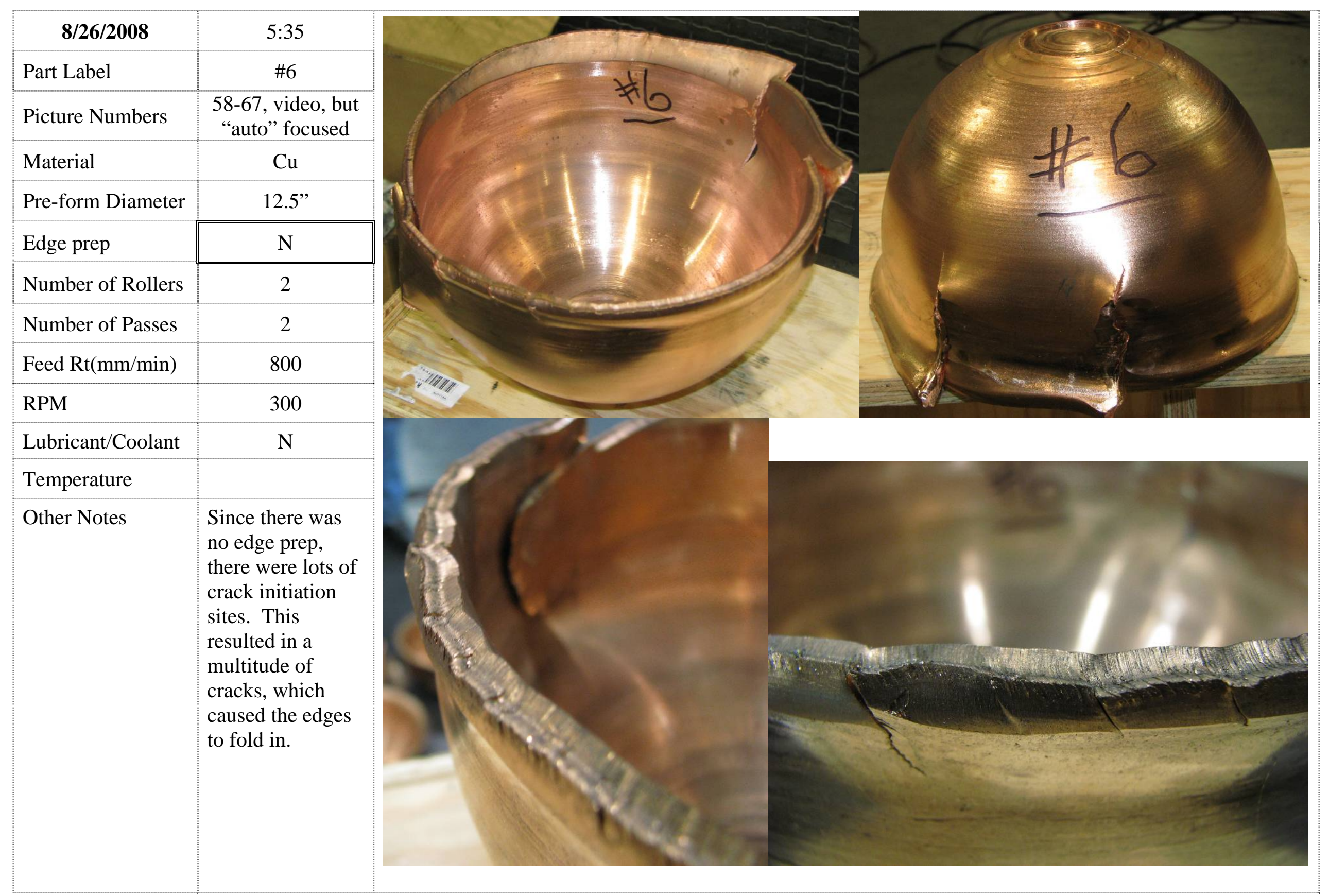


Appendix C: Results of Spin-Form Development Order 2

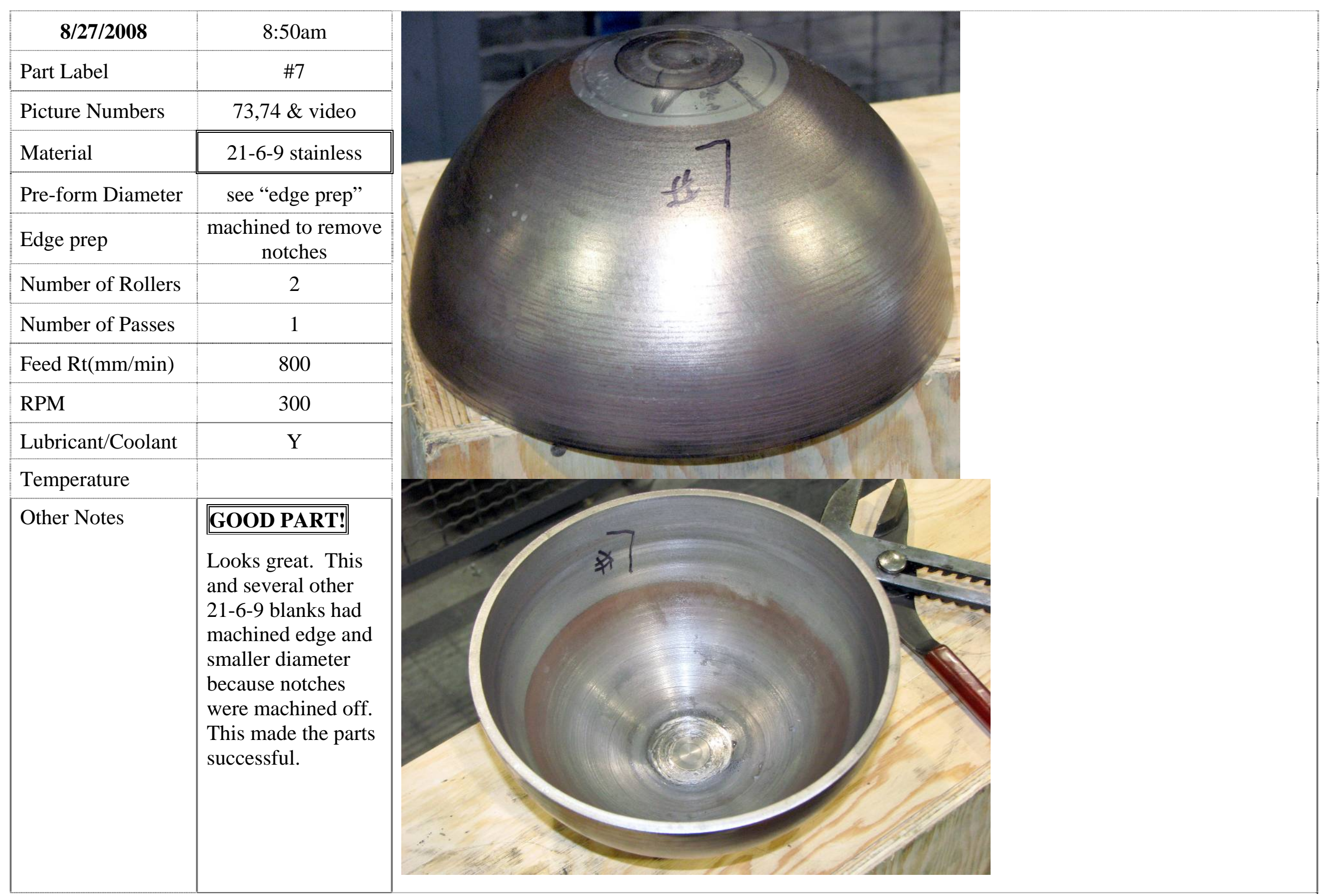


Appendix C: Results of Spin-Form Development Order 2

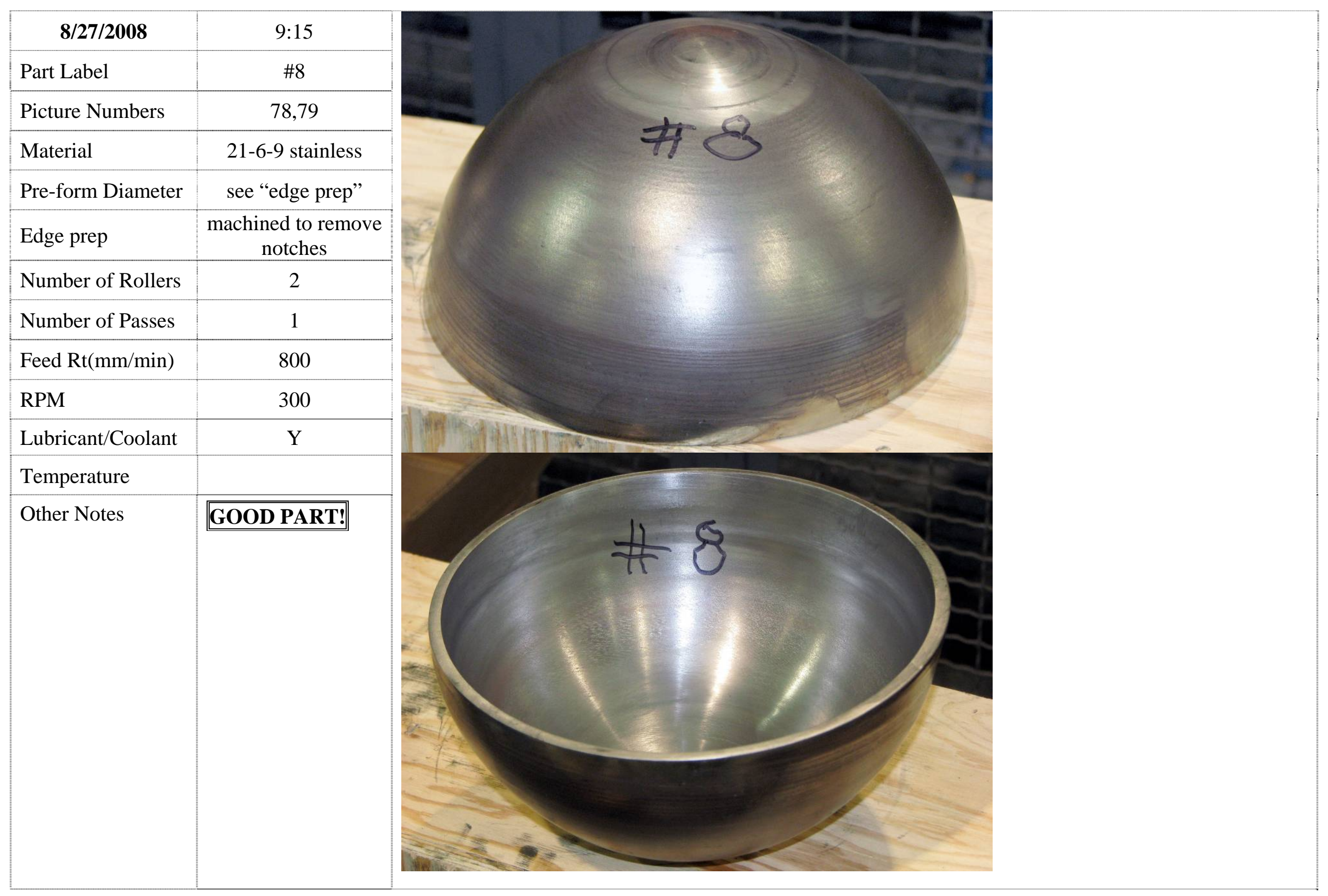


Appendix C: Results of Spin-Form Development Order 2

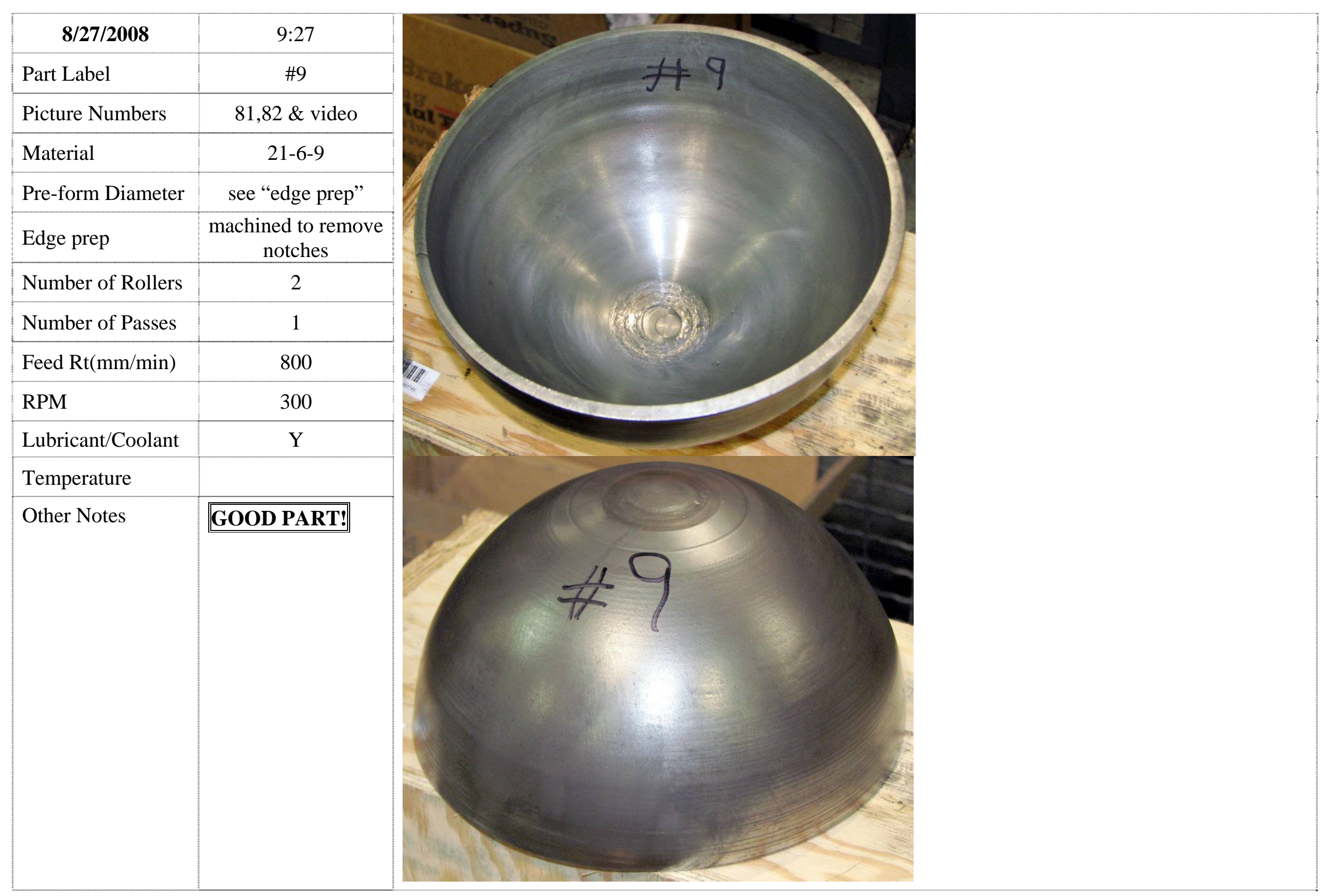


Appendix C: Results of Spin-Form Development Order 2

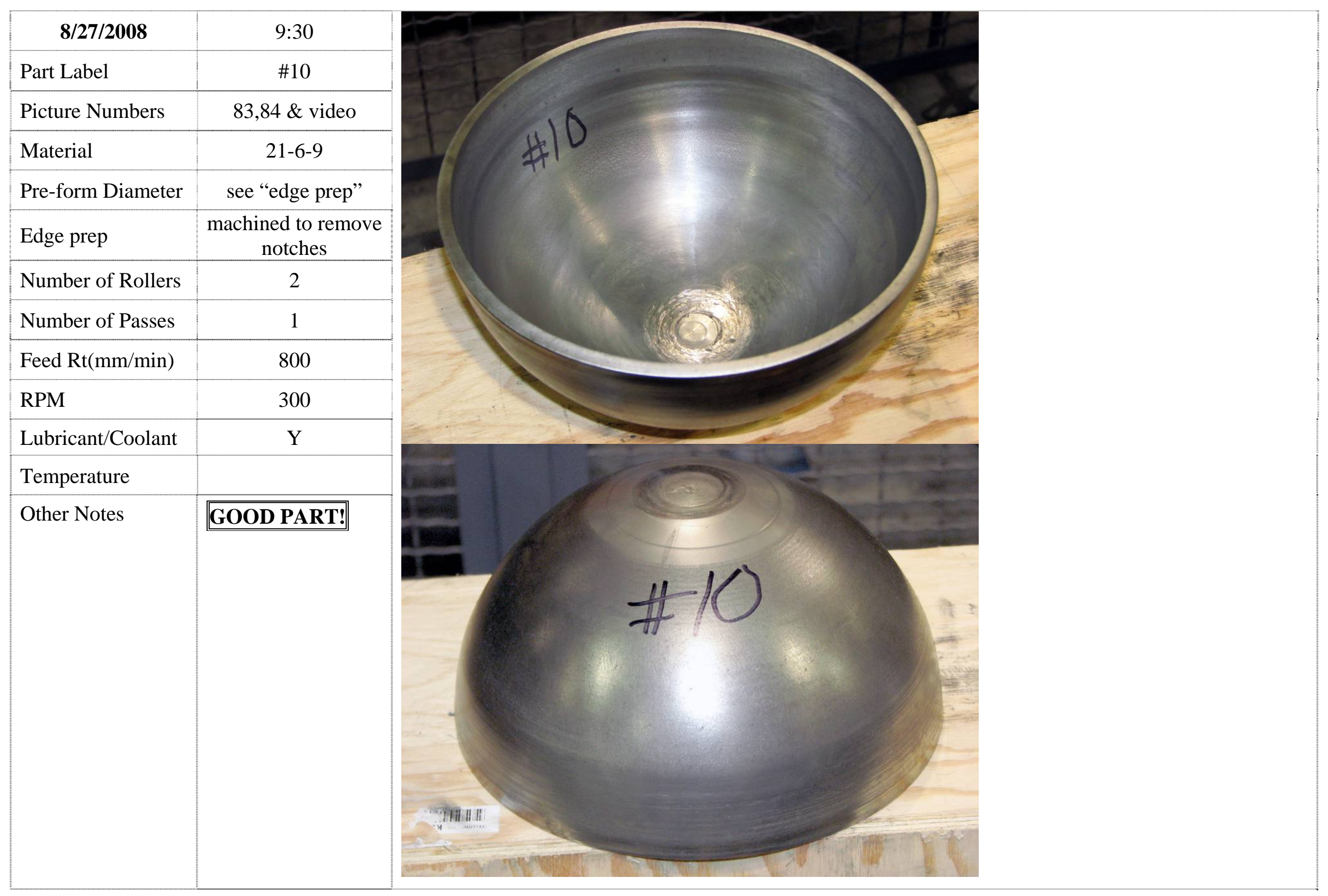


Appendix C: Results of Spin-Form Development Order 2

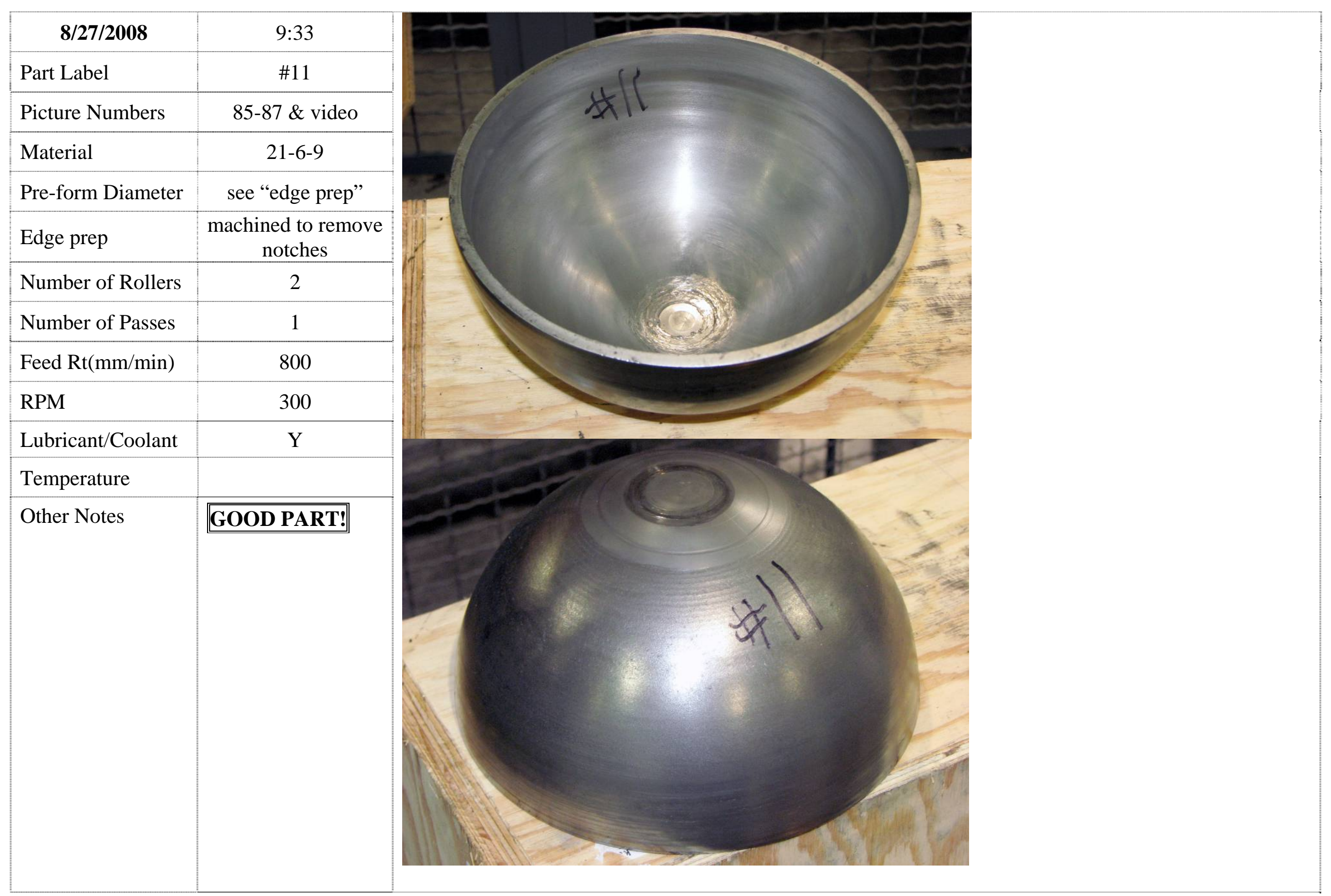


Appendix C: Results of Spin-Form Development Order 2

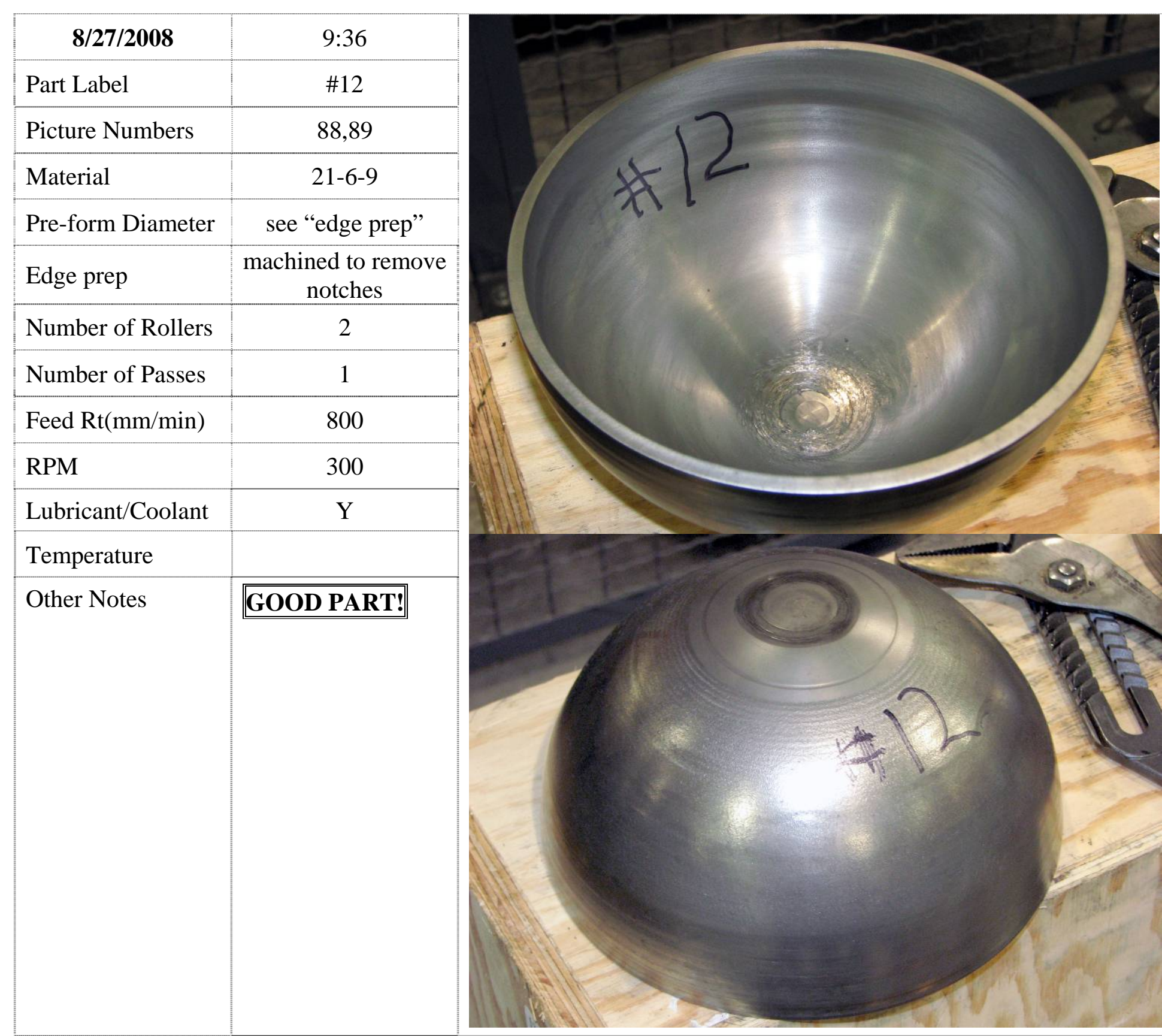


Appendix C: Results of Spin-Form Development Order 2

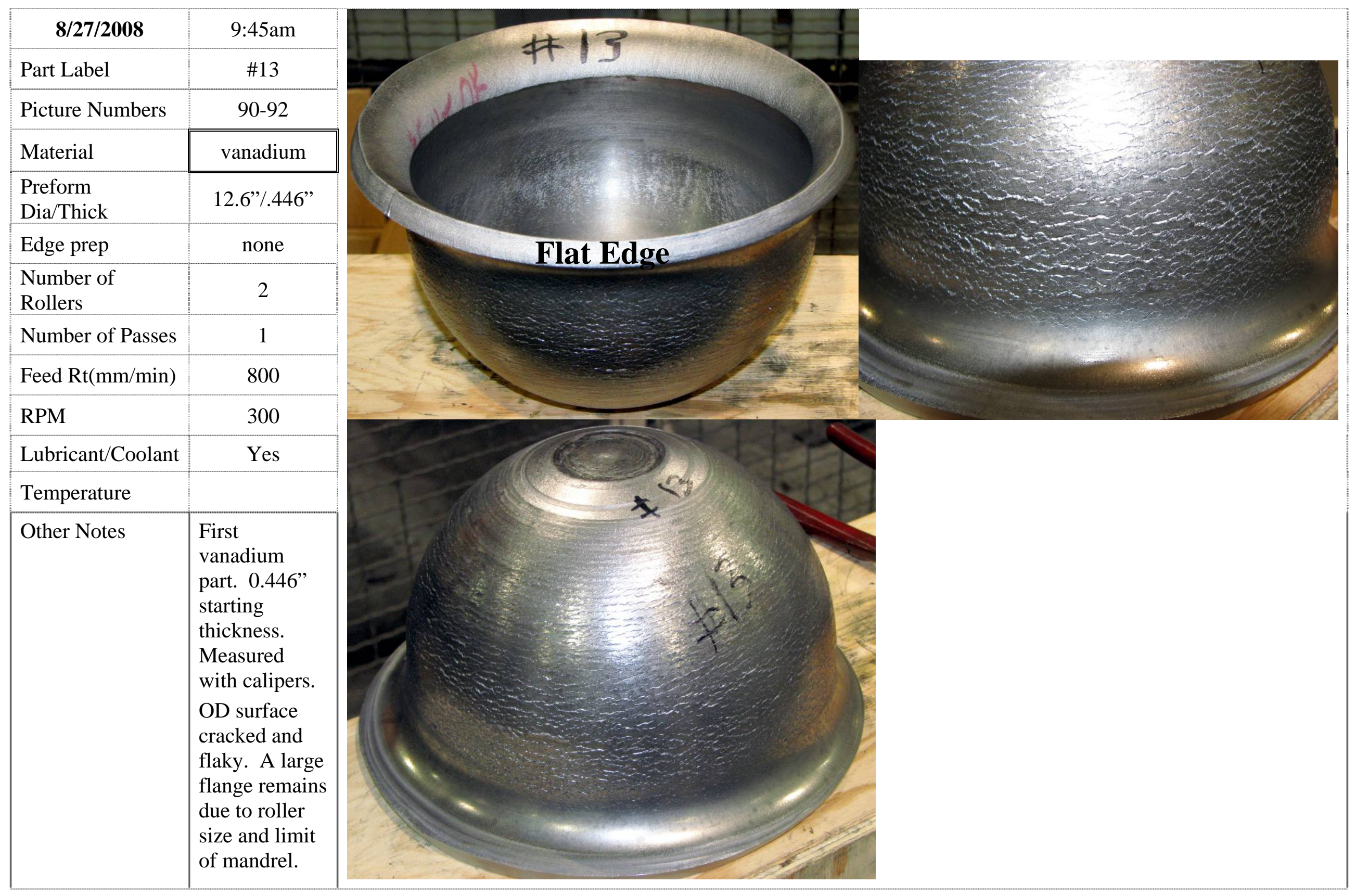




\section{Appendix C: Results of Spin-Form Development Order 2}

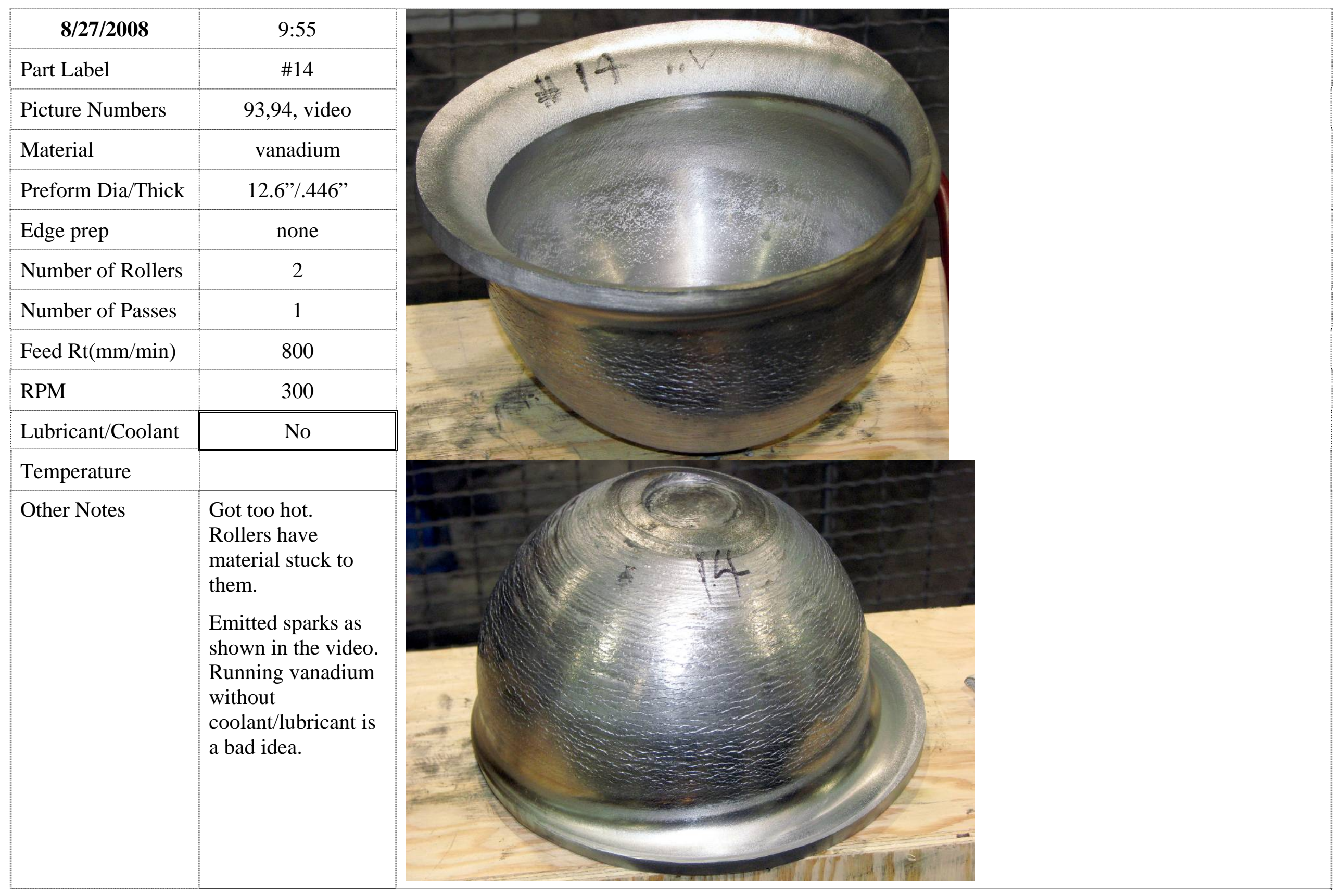


Appendix C: Results of Spin-Form Development Order 2

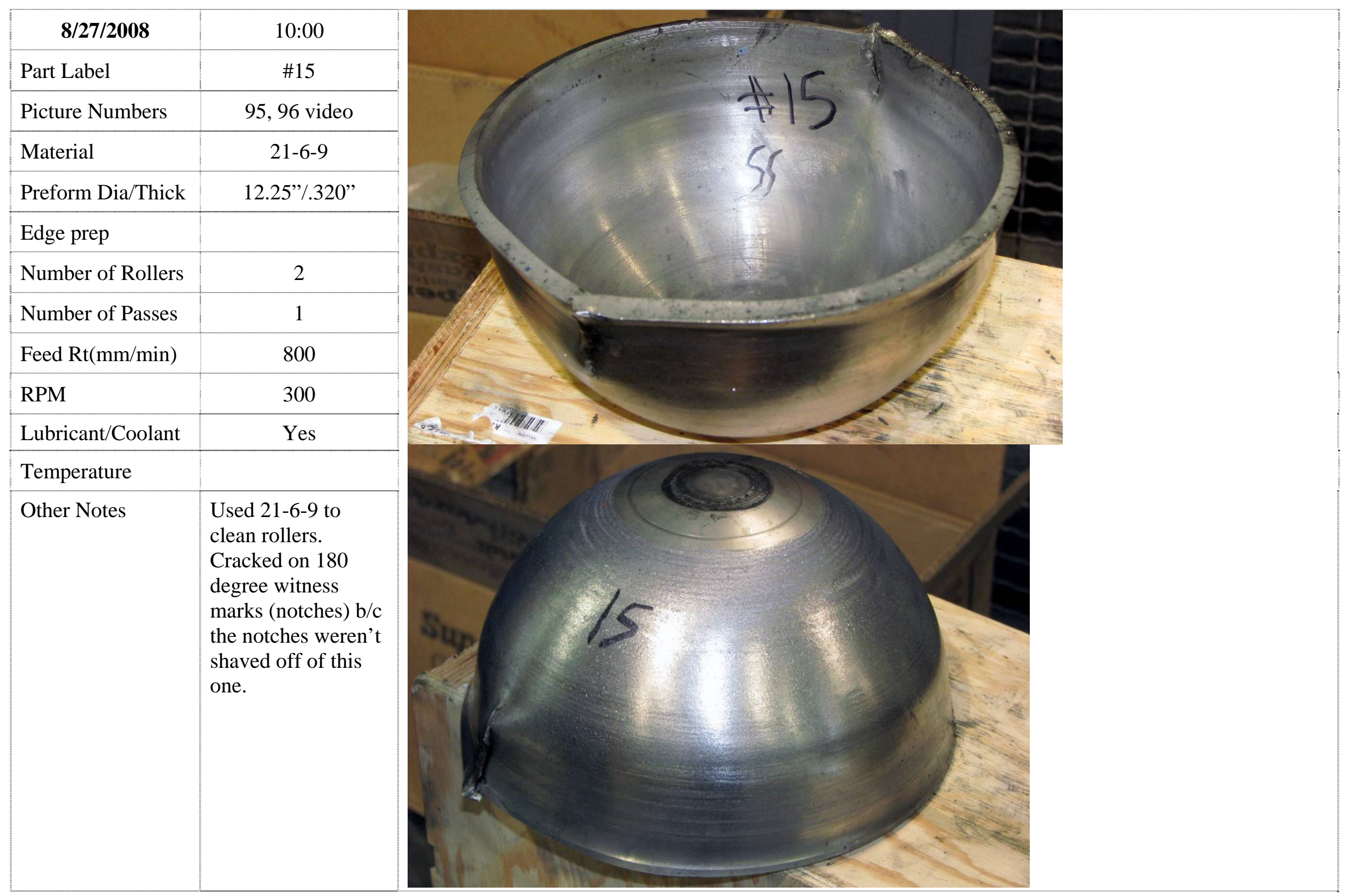


Appendix C: Results of Spin-Form Development Order 2

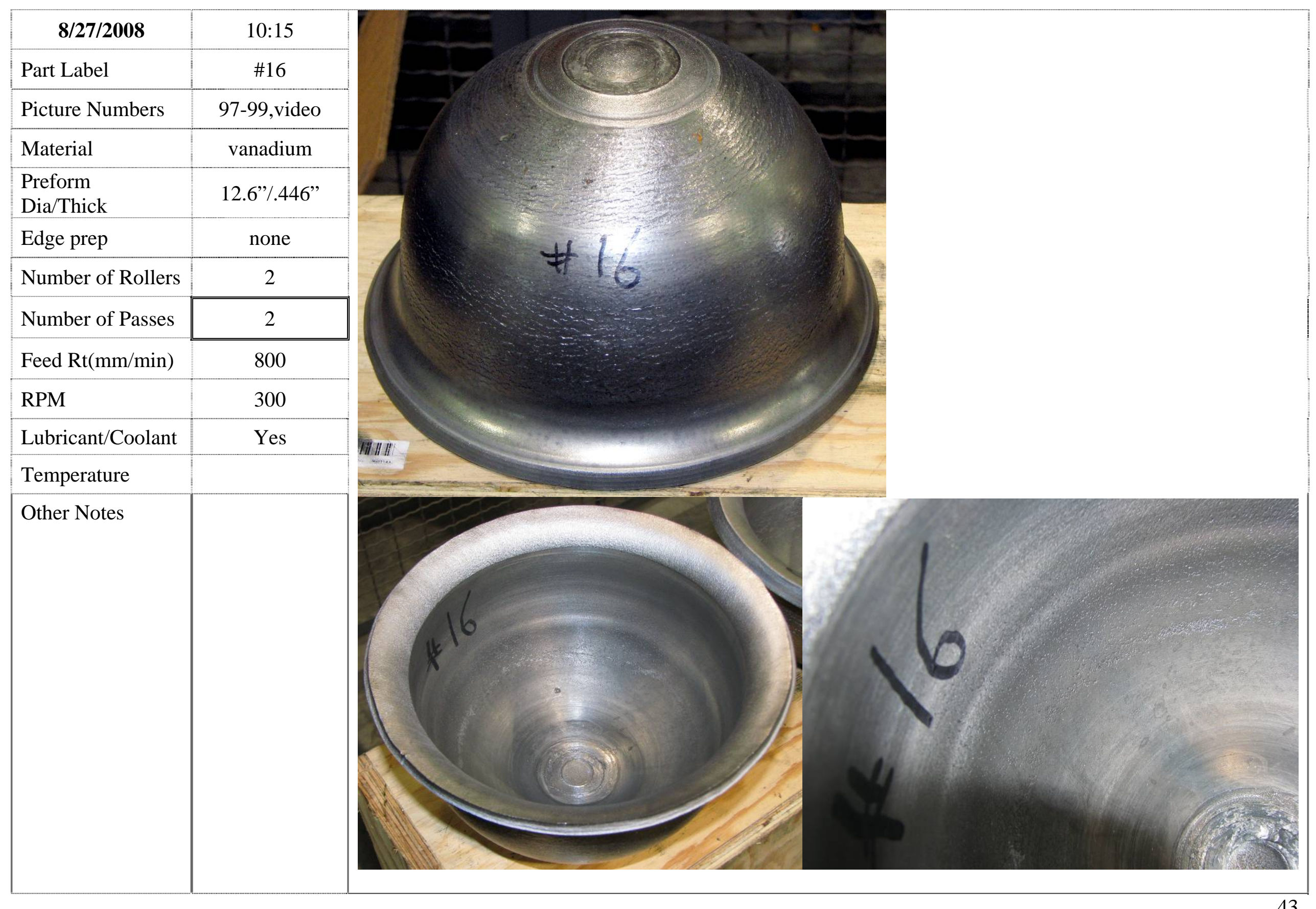




\section{Appendix C: Results of Spin-Form Development Order 2}

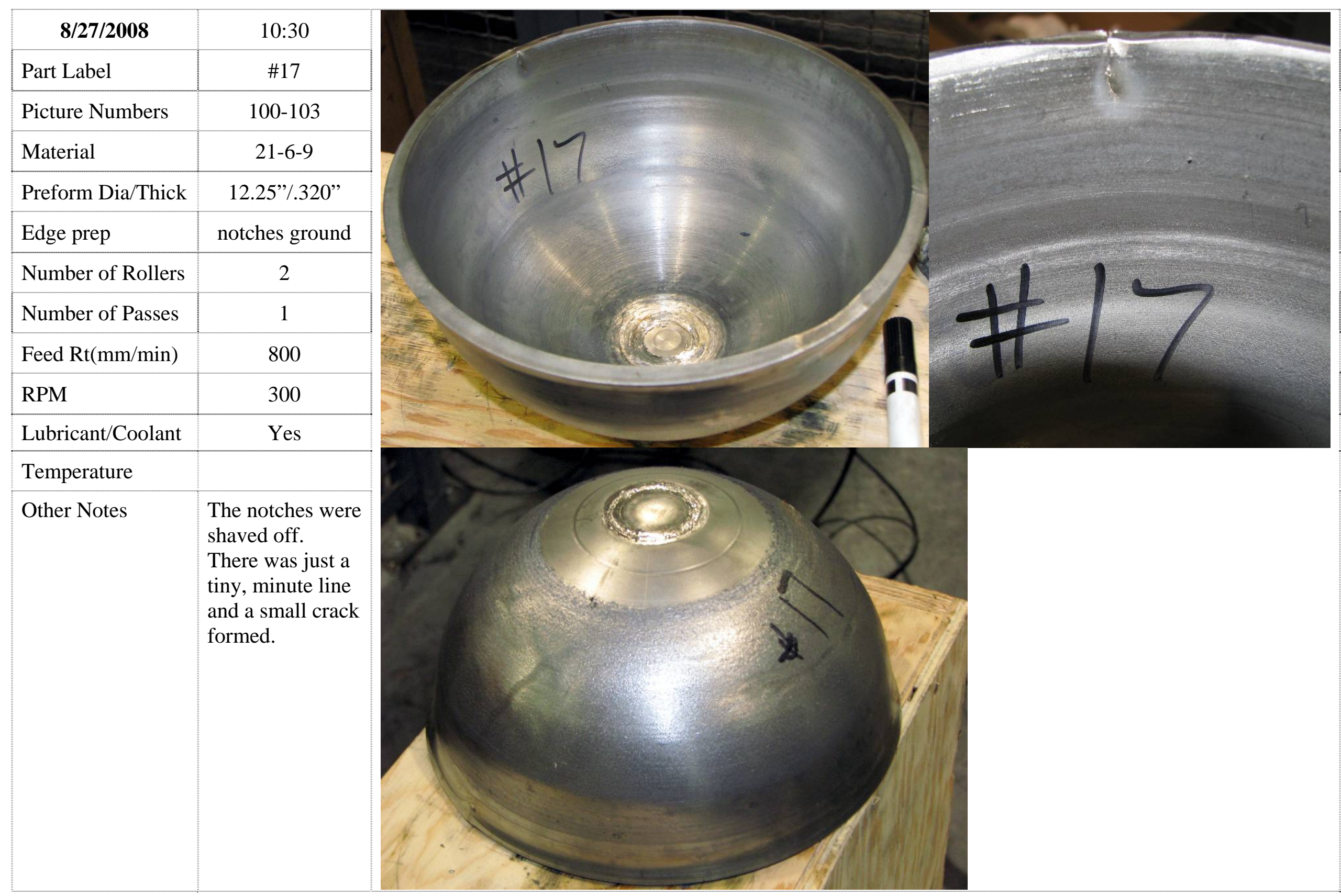


Appendix C: Results of Spin-Form Development Order 2

\begin{tabular}{|c|c|c|c|}
\hline $8 / 27 / 2008$ & $10: 44$ & & \\
\hline Part Label & $\# 18$ & & \\
\hline Picture Numbers & 104,105 , video & s. & \\
\hline Material & vanadium & & $x_{1}$ \\
\hline Preform Dia/Thick & $12.6 ” / .446 "$ & & 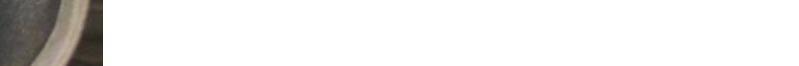 \\
\hline Edge prep & none & & 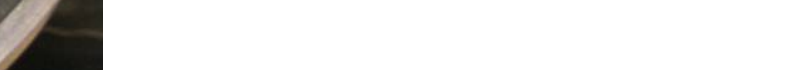 \\
\hline Number of Rollers & 2 & & 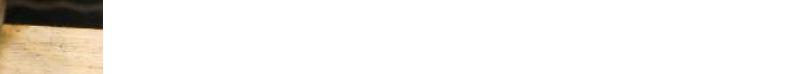 \\
\hline Number of Passes & 4 & & 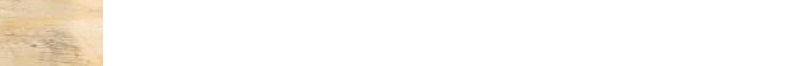 \\
\hline Feed Rt(mm/min) & 800 & & 㬈 \\
\hline RPM & 300 & & \\
\hline Lubricant/Coolant & Yes & & 5 \\
\hline \multicolumn{4}{|l|}{ Temperature } \\
\hline Other Notes & $\begin{array}{l}\text { Improvement over } \\
\text { 2-pass. } \\
\text { There's a band of } \\
\text { material with no } \\
\text { surface cracking on } \\
\text { both } 2 \& 4 \text { passes, } \\
\text { but on } 4 \text { passes this } \\
\text { band is thicker, so } \\
\text { we're going to try } 9 \\
\text { passes. }\end{array}$ & 8 & \\
\hline
\end{tabular}


Appendix C: Results of Spin-Form Development Order 2

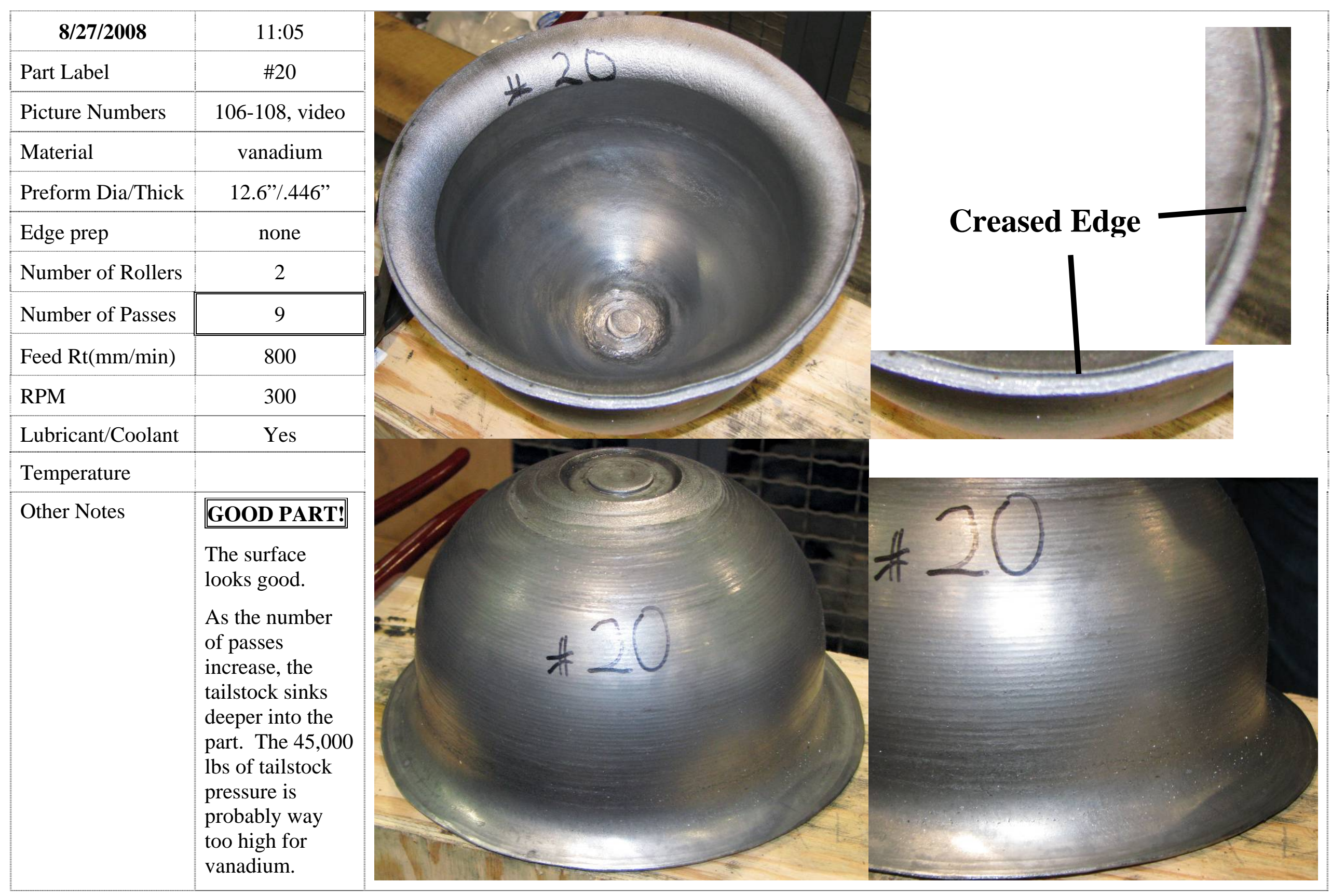


Appendix C: Results of Spin-Form Development Order 2

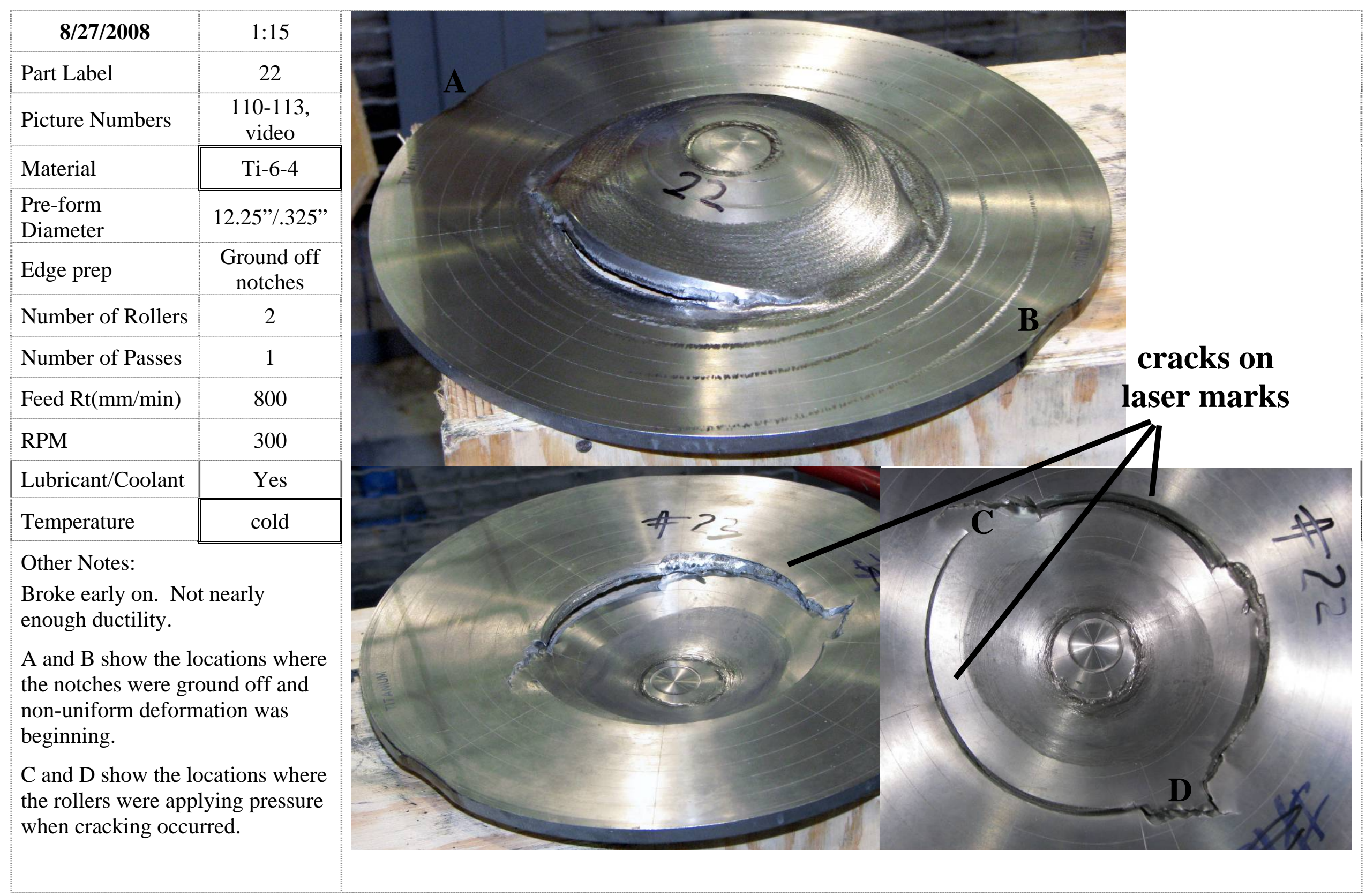


Appendix C: Results of Spin-Form Development Order 2

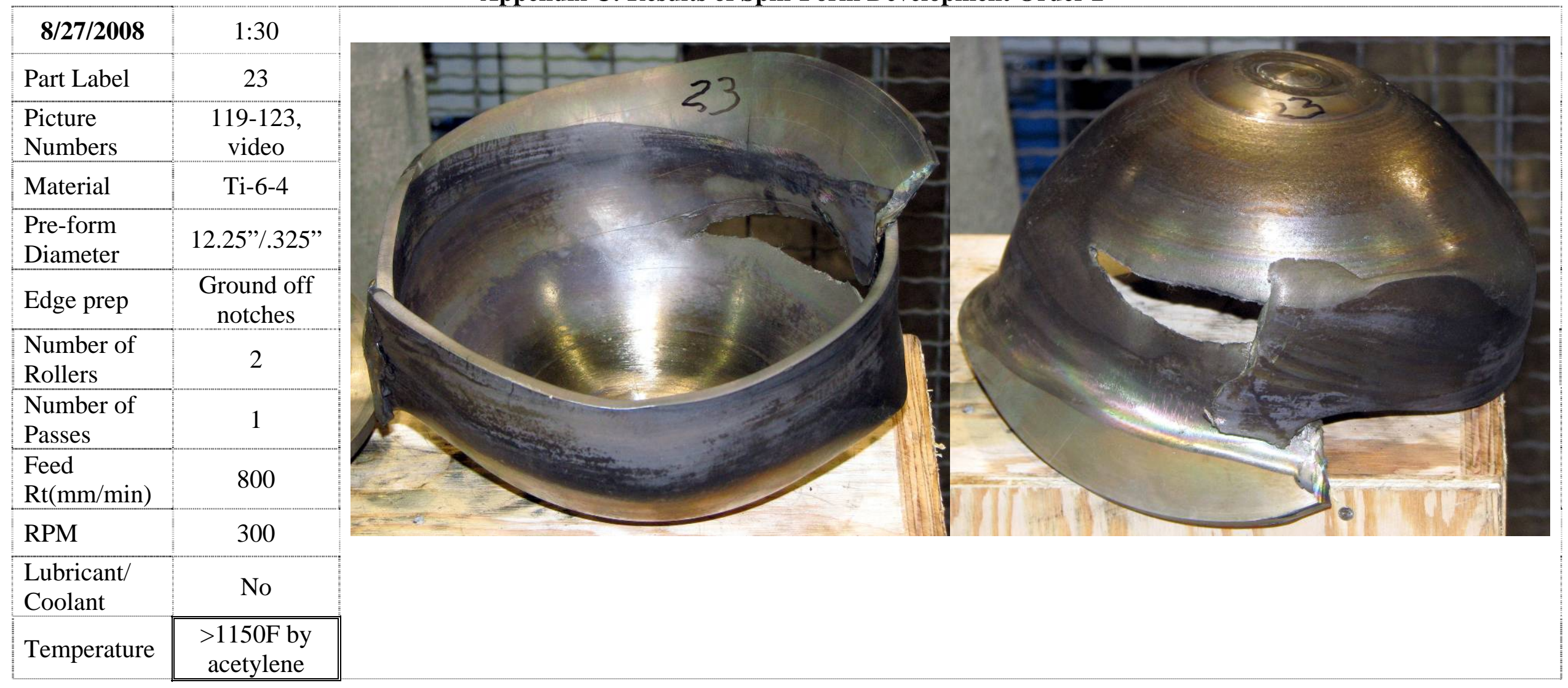




\begin{tabular}{|c|c|}
\hline Other Notes & $\begin{array}{l}\text { Took several } \\
\text { minutes to } \\
\text { heat. } \\
\text { A thin yellow } \\
\text { line of very } \\
\text { hot Ti was } \\
\text { visible in } \\
\text { front of the } \\
\text { roller as it } \\
\text { progressed, } \\
\text { believed to } \\
\text { be due to } \\
\text { heating from } \\
\text { internal } \\
\text { friction from } \\
\text { plastic } \\
\text { deformation. }\end{array}$ \\
\hline
\end{tabular}

\begin{tabular}{|l|c|}
\hline \multicolumn{1}{|c|}{$\mathbf{8} / \mathbf{2 7 / 2 0 0 8}$} & $2: 15$ \\
\hline Part Label & 24 \\
\hline Picture Numbers & 128-132, video \\
\hline Material & Ti-6-4 \\
\hline Pre-form Diameter & 12.25”/.325” \\
\hline Edge prep & Ground off notches \\
\hline Number of Rollers & 2 \\
\hline Number of Passes & 1 \\
\hline Feed Rt(mm/min) & 800 \\
\hline RPM & 300 \\
\hline Lubricant/Coolant & No \\
\hline
\end{tabular}

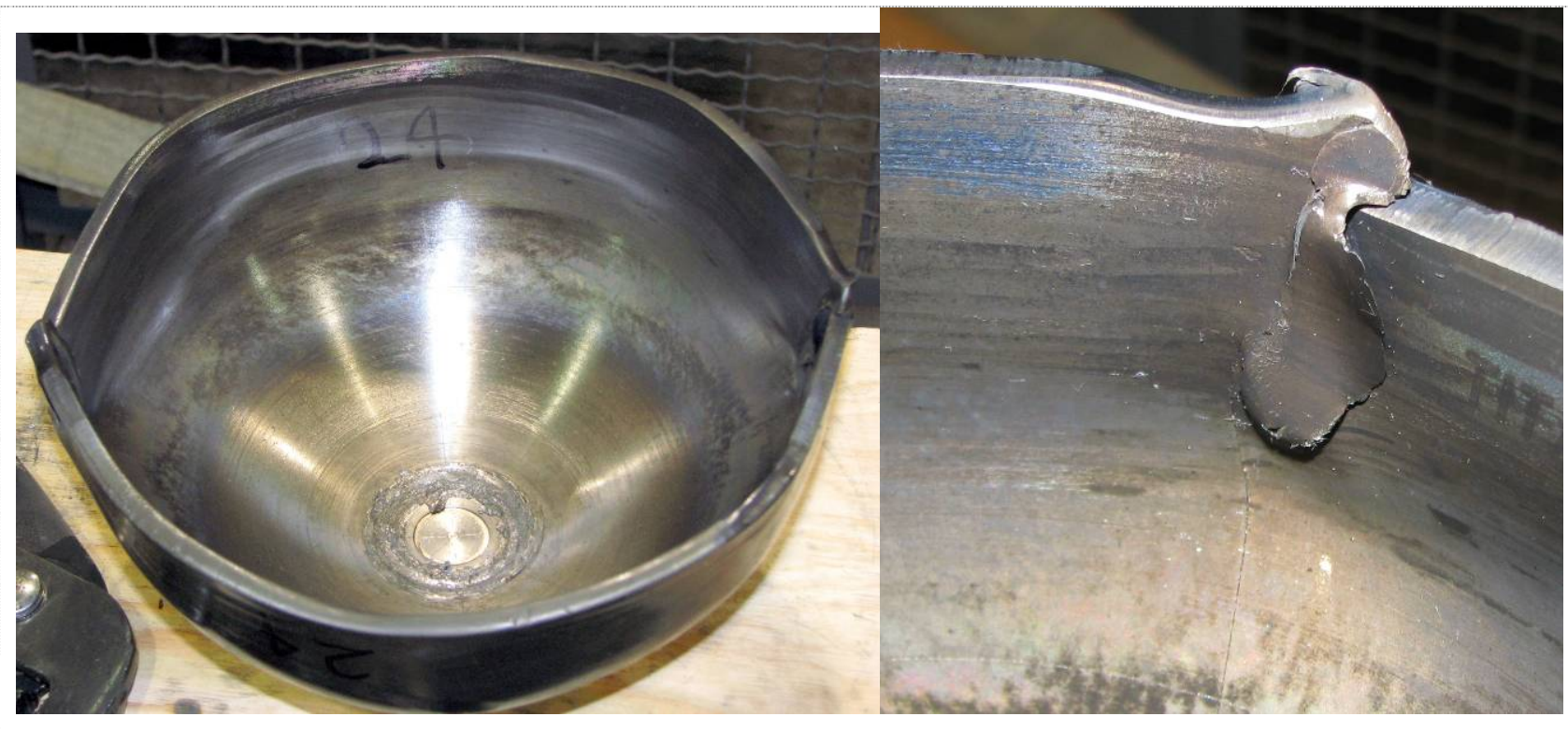




\section{Appendix C: Results of Spin-Form Development Order 2}

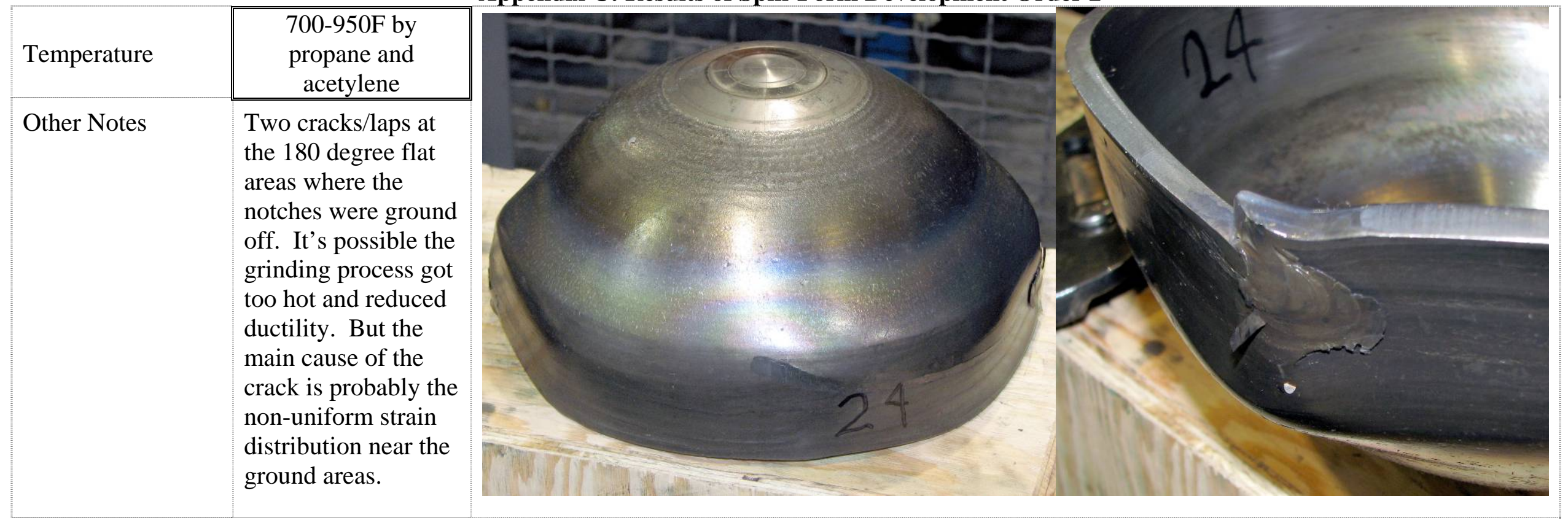

\begin{tabular}{|l|c|}
\hline \multicolumn{1}{|c|}{$\mathbf{8} / \mathbf{2 7 / 2 0 0 8}$} & $3: 40$ \\
\hline Part Label & 25 \\
\hline Picture Numbers & $133-140$, video \\
\hline Material & Ti-6-4 \\
\hline Pre-form Diameter & $12.25 \% / .325 ”$ \\
\hline Edge prep & Sanded off notches \\
\hline Number of Rollers & 2 \\
\hline Number of Passes & 1 \\
\hline Feed Rt(mm/min) & 800 \\
\hline RPM & 300 \\
\hline Lubricant/Coolant & No \\
\hline
\end{tabular}


Appendix C: Results of Spin-Form Development Order 2

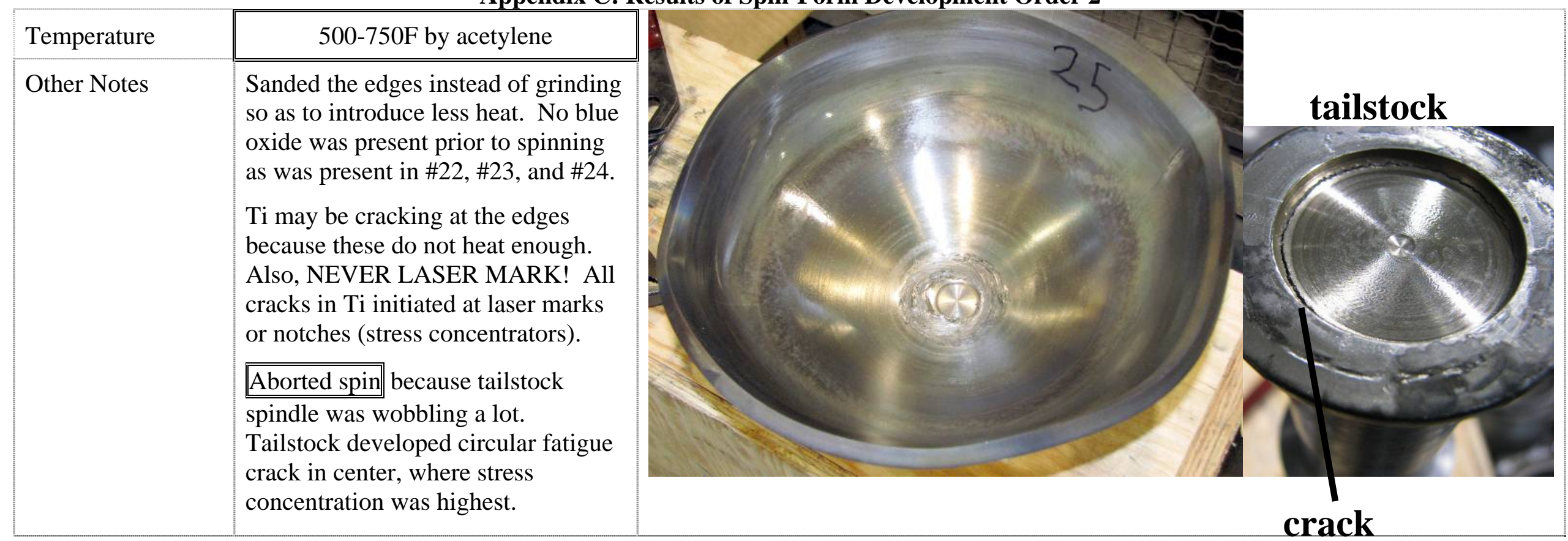

